\title{
External Financing and the Role of Financial Frictions over the Business Cycle: Measurement and Theory*
}

\author{
Ali Shourideh \\ NYU and Wharton \\ shouride@wharton. upenn.edu
}

Ariel Zetlin-Jones

$\mathrm{UMN}$

zetli001@umn.edu

January 16, 2012

\begin{abstract}
We examine the quantitative importance of financial market shocks in accounting for business cycle fluctuations. We emphasize the role financial markets play in reallocating funds from cash-rich, low productivity firms to cash-poor, high productivity firms. We use evidence on financial flows to analyze the importance of this role of financial markets. This evidence shows that in the aggregate, funds available to firms internally are more than adequate to finance investment. At the firm level, we find that for publicly traded firms (in Compustat), almost all investment is financed internally while, using a alternative data source (Amadeus), we find that most investment by privately held firms is financed through borrowing. These observations suggest that the quantitative impact of financial market shocks depend both on the sensitivity of investment and output of privately held firms to such shocks and on the extent to which the investment and output of publicly held firms respond to the actions of privately held firms. Motivated by these observations, we build a quantitative model featuring publicly and privately held firms that face collateral constraints and idiosyncratic risk over productivity. We model financial market shocks as shocks to the collateral constraints. In our model, each firm has a monopoly in producing a differentiated good and uses the goods produced by other firms as an input for production - features that create non-financial linkages between publicly and privately held firms. In our calibrated model, we find that a shock to the collateral constraints which generates a one standard deviation decline in the debt-to-asset ratio leads to a $0.5 \%$ decline in aggregate output on impact, roughly comparable to the effect of a one standard deviation shock to aggregate productivity in a standard real business cycle model. In this sense, we find that disturbances in financial markets are a promising source of business cycle fluctuations when non-financial linkages across firms are sufficiently strong.
\end{abstract}

${ }^{*}$ We are indebted to V.V. Chari and Larry Jones for valuable advice. We would also like to thank Narayana Kocherlakota, Chris Phelan, Warren Weber, and the Chari-Jones workshop, especially Alessandro Dovis and Erick Sager, for helpful comments. 


\section{Introduction}

One role of financial markets is to reallocate capital from cash-rich, low productivity firms to cash-poor, high productivity firms. In this paper, we examine the importance of shocks to the ability of financial markets to reallocate capital for the magnitude and duration of business cycles. In particular, we focus on the role of financial markets in funding investment. In the aggregate, data from the flow of funds shows that internal funds generated by firms is more than adequate to finance investment. This observation might lead an observer to think financial market shocks would have very modest business cycle effects. We argue, however, looking only at the aggregates may be misleading. New evidence on privately held firms (in the Amadeus data set) shows that almost all of investment by such firms is financed through borrowing. This data suggests that disruptions to the reallocative role of financial markets could have a large impact on the investment and output of privately held firms and, through spillovers on other firms, on aggregate economic activity. The size of the impact depends critically both on the sensitivity of investment and output of privately held firms to shocks to financial markets and on the extent to which there are spillovers from the actions of privately held firms to the investment and output decisions of publicly held firms.

To analyze the quantitative importance of financial market shocks, we develop a model in which firms are subject to idiosyncratic shocks so that it is desirable to reallocate capital from low productivity firms to high productivity firms, but financial frictions impede this reallocation. We model these frictions as collateral constraints and disturbances in the ability of financial markets to reallocate capital as shocks to collateral constraints. Our approach follows a substantial literature that has examined the role of financial market frictions over the business cycle (see Bernanke et al. (1999), Kiyotaki and Moore (2008), and Jermann

and Quadrini (2011) to cite just three examples). We discipline our quantitative exercise by using data on financial flows.

Our model differs from those in the existing literature by incorporating three key ingredients. First, data on financial flows shows that at the aggregate level, firms generate internal funds substantially in excess of what they need to finance operations and investments. Thus, if financial market frictions affect investment over the business cycle, they must affect the reallocation of funds among firms rather than impeding the ability of firms to obtain investment funds from households. To allow for reallocation problems among firms, our model features heterogeneous firms in the sense that each individual firm faces idiosyncratic risk and incomplete markets.

Second, the evidence from Compustat shows that for publicly traded firms, almost all capital expenditures can be financed using internal funds. We show, however, that the bulk of 
capital expenditures by privately held firms is financed through borrowing. To be consistent with this large observed difference between the two types of firms in the data, our model features both publicly held and privately held firms, each of which face potentially binding collateral constraints. The difference between these types of firms is that publicly held firms are owned by households that can better insure themselves against the idiosyncratic risk affecting a particular firm than can owners of privately held firms.

Third, a key feature of the data is that firms use intermediate goods produced by other firms as well as capital and labor to produce gross output. This observation implies that firms are naturally connected with each other through trade linkages. We model these connections by assuming that each firm in our model has a monopoly in producing a differentiated good and uses the goods produced by other firms as an intermediate good in production. We show that under reasonable parameter assumptions regarding the fraction of gross output that represents use of intermediate goods and on the size of markups, these linkages across firms can generate co-movement of output by publicly held and privately held firms in response to financial market shocks. These linkages also play an important role in amplifying the quantitative effects of financial shocks.

In our calibrated model, we find that a shock to the collateral constraints which generates a one standard deviation decline in the aggregate debt-to-asset ratio leads to a $0.5 \%$ decline in aggregate output on impact. This decline is roughly comparable to the effect of a one standard deviation shock to aggregate productivity in a standard real business cycle model. A collateral constraint shock also leads to a sizable decline in consumption, investment and employment. We also find that shocks to collateral constraints induce persistent effects on aggregates. In this sense, we find that disturbances in financial markets are a promising source of business cycle fluctuations.

Firm heterogeneity plays a central role in generating our results. In our model firms face idiosyncratic shocks to productivity and collateral constraints in accumulating capital. We argue that a representative firm version of our model in which the collateral constraint binds is inconsistent with aggregate data on financial flows in both the United States and Europe. Specifically, in both the U.S. and the U.K., after paying for interest, taxes, payments to labor and other businesses for materials, the non-financial business sector in the aggregate generates funds, which we call Available Funds, substantially in excess of funds used for investment. This observation implies that it is difficult for macroeconomic models with a representative firm subject to collateral constraints to produce large fluctuations in investment and output in response to a tightening of collateral constraints. One reason is that shareholders of firms have strong incentives to accept delayed payments in dividends so as to relax current collateral constraints. 
Our quantitative results are disciplined by data on firm level use of external funds for investment. Disaggregated data on publicly held firms in the U.S. and the U.K. and on privately held firms in the U.K. suggests that it is important to distinguish between these subsets of firms. We develop a statistic to measure how much a subset of firms rely on external financing. In particular, our statistic measures the amount of external funds used for investment by firms. We find that in both the U.S. and the U.K., on average (over time) roughly $20 \%$ of investment by publicly held firms is externally financed so that $80 \%$ of investment by firms is finaced by available funds. In the U.K., on average roughly $90 \%$ of investment by privately held firms is externally financed so that only $10 \%$ of investment is financed by available funds.

This observation motivates us to introduce a second type of heterogeneity in our model. Specifically, we partition firms into those that are owned by diversified households, and therefore better able to insure themselves against idiosyncratic risk and those that are owned by entrepreneurs who cannot insure themselves against idiosyncratic risk. The observation that privately held firms use external funds for investment to a much greater extent than do publicly held firms suggests that the role played by financial markets in reallocating capital for investment is more important for privately held firms than it is for publicly held firms. In this sense, privately held firms are more likely to be affected by disturbances to their collateral constraints than are publicly traded firms.

In our model, collateral constraints are present for both types of firms. Both public and private firms can borrow up to a level proportional to their asset holding. Both types of firms are limited in their access to financial markets, in the sense that they must borrow using debt. We assume that, in addition to productivity risk, firms are subject to bankruptcy risk so that the effective discount rate is higher than the interest rate for privately held firms. However, because publicly held firms are owned by diversified households, the bankruptcy risk does not raise the effective discount rate of publicly held firms. These differences in effective discount factors imply that, in a stationary equilibrium, publicly held firms have sufficient asset holdings so that the collateral constraint does not bind, whereas privately held firms face occasionally binding constraints. The differences in the extent to which collateral constraints bind implies that privately held firms are much more reliant on external funds for investment than are publicly held firms.

Trade linkages across firms ensure that output and investment of different types of firms move together. We assume that each firm, both public and private, produces a differentiated good and there is monopolistic competition between different firms a la Dixit-Stiglitz. Moreover, we assume that each firm uses a bundle of goods produced by other firms as an input as well as capital and labor. These elements capture observed markups and the observation 
that gross output is roughly twice as large as value added.

In our quantitative model, under our assumed parameter values, a tightening of collateral constraints lead to a decline in output. The economic mechanism that drives this result is that for privately held firms a tightening of the collateral constraint decreases the demand for capital by firms for whom the collateral constraint binds. For such firms, the decrease in capital demand leads to a decrease in demand both for labor and for intermediate goods to be used in production. As a result, the rental rate of capital and the wage rate both decline, tending to raise the output of unconstrained firms. However, the fall in the wage and capital rental rate results in a negative wealth shock to households and privately held firms, causing a decline in demand for the final good - both for consumption and as an intermediate input in production. Because goods are not perfect substitutes, demand for goods produced by all firms falls, tending to lower output of unconstrained firms. Thus, a tightening of collateral constraints has competing effects on the production of firms for whom the collateral constraint does not bind. The effect of the shock on aggregate demand and intermediate good production provide incentives for unconstrained firms to decrease production while the effect of the shock on wages and interest rates provide incentives for unconstrained firms to increase production. We show that under our reasonable parameter assumptions, the aggregate demand and intermediate good effects dominate so that a tightening of collateral constraints leads unconstrained firms to decrease their production.

We calibrate our quantitative model with both publicly and privately firms to be consistent with four key facts from the financial flows data. We require the model to replicate the share of gross output accounted for by privately held firms, the aggregate debt-to-total assets ratio for all firms, the dispersion of the firm level debt-to-total assets ratio among privately held firms, and the amount of external funds used for investment by privately held firms. We show that these facts in the data help determine the quantitative importance of disturbances to the collateral constraints in the model.

We then perform an impulse response analysis from the steady state of our calibrated model. Specifically, we shock the economy with a partially persistent disturbance to the collateral constraint which generates a one standard deviation decline in the debt-to-total assets ratio of privately held firms on impact. We find that such an impulse generates a $0.5 \%$ decline in aggregate output on impact. Although sales of publicly held firms initially rise on impact, partially off-setting the initial decline in sales by privately held firms, within two periods they fall below the steady state level. The non-financial linkages we introduce play an important role, both in dampening the initial response of publicly held firms and in generating co-movement in sales after the second period of the shock.

Related Literature. Our paper is related to an extensive literature on the effect of 
financial frictions in macroeconomics, starting from Bernanke and Gertler (1989), Carlstrom and Fuerst (1997), Kiyotaki and Moore (1997), Bernanke et al. (1999) and more recently Kiyotaki and Moore (2008) and Jermann and Quadrini (2011). The common goal is to identify and understand the channels through which financial market disruptions affect economic activity and their quantitative importance. Our goal in this paper is the same while our approach differs in that we use data on external financing to discipline the importance of these channels.

Our empirical work on external financing needs is related to a literature in corporate finance which attempts to identify the extent to which firms face constraints in financing their investment (see Fazzari et al. (1988), and Gilchrist and Himmelberg (1995) among many others). ${ }^{1}$ The approach in this literature is to test the implications of models with financing constraints, namely that Tobin's Q as well as cash-flow would have a significant effect on investment. Our approach, however, differs from theirs in that our measurement approach emphasizes the role of financial markets in firms' financing decision, i.e., how much of their investment is financed using external funds. In this regard, our approach is closer to the one taken by Rajan and Zingales (1998) and Buera et al. (2011). Additionally, this measurement approach allows us to abstract from which firms in particular face binding financing constraints while disciplining the importance of financial markets for investment.

From a modeling perspective, our model of financial frictions is a natural extension of Evans and Jovanovic (1989) to dynamic environments. The basic structure of the model is very similar to Gomes (2001). While he models financial frictions as additional costs to external financing, we follow Evans and Jovanovic (1989) and assume that investment is bound by a factor of net worth. Our model is also related to an extensive series of papers on the effect of idiosyncratic investment risk on firm dynamics and its financial structure including Cooley and Quadrini (2001), Hennessy and Whited (2005), and Angeletos (2007) to name a few.

Our modelling approach is also similar to an extensive literature that analyzes the effects of financial frictions on misallocation and Total Factor Productivity, such as Midrigan and Xu (2010), Buera et al. (2011), and Moll (2011). While our basic model is very similar, aside from inclusion of monopolistic competition and intermediate goods as inputs, we focus on shortterm dynamics of the model. Moreover, because of our focus on business cycle frequency fluctuations and the importance of the role played by financial markets, our calibration is somewhat different. In particular, we calibrate the model to match evidence on external financing as well as the variance of debt to asset ratios while the papers mentioned above focus on the dynamics of firm size. While these measures are correlated, our focus on financial

\footnotetext{
${ }^{1}$ Kaplan and Zingales (1997) question the validity of this approach.
} 
flows and external financing makes our paper different from theirs. Moreover, our firm level employment dynamics closely resembles the evidence documented by Davis et al. (2007).

Our quantitative exercise is most closely related to Jermann and Quadrini (2011) where shocks to financial constraints cause fluctuations in economic activity. Our analysis, however, is substantially different from theirs. They focus on a model with a representative firm that is financially constrained and which faces exogenously specified cost of reducing dividends to finance investment. One way of thinking about our paper is that we develop a model in which the cost of reducing dividends are endogenous, in the sense that for privately held firms, dividend reductions affect the marginal utility of consumption of entrepreneurs. We think of their paper as a first step toward developing a workhorse model for analysis of shocks to financial markets and the effect of such shocks on real activity. In this paper, we take the next step and show that there is a great deal of heterogeneity in firms' reliance on external financing. This helps us impose further discipline on our model of financial frictions and firm heterogeneity and the mechanisms that translate financial shocks to the real economy. Our paper is also related to a number of studies that focus on how presence of financial frictions amplify and propagate the effect of productivity shocks to the economy such as Khan and Thomas (2011) and Nezafat and Slavik (2011). Furthermore, our transitional dynamic exercise is very similar to Guerrieri and Lorenzoni (2011), however, they focus on changes in household's borrowing opportunities while we focus on the production side of the economy.

The paper is organized as follows: in section 2 we provide evidence on firms' external financing behavior, in section 3 contains our model and its theoretical analysis, section 4 contains our quantitative exercise, section 5 concludes.

\section{Evidence on External Financing Needs}

In this section, we present evidence on the use of external funds for investment in the aggregate and at the firm level in the United States and in the United Kingdom. We show that in the aggregate, firms can self-finance the entirety of their investments. We also show that privately held firms externally finance a significant fraction of their investment while publicly held firms externally finance much less of their investment. We conclude by presenting evidence that the difference in the reliance on external financing between publicly held and privately held firms holds even when we focus on firms of approximately the same size.

We begin this section by discussing the conceptual objects we intend to study. We then describe our data sources and how we measure the use of external funds for investment in 
our different data sources. We then outline the key facts on external financing.

\subsection{Conceptual Measurement of Financial Flows}

We construct an empirical measure of the amount external funds that a firm requires to fund its investment. One way to measure this external financing need is to measure net financial inflows or outflows for firms. By definition, if a firm's investment in any period is greater than the amount of funds generated from operations after paying for interest, legal obligations, payments to labor and other businesses for materials, then the firm must receive net financial inflows. To the extent that available funds are fixed, one less dollar of financial inflows would lead necessarily to a one dollar decline in investment. On the other hand, if a firm's amount of investment is less than its fund generated from operations, then the firm has the ability to self finance the entirety of its investment if it so chooses.

It is easiest to understand these definitions by considering the budget constraint of a firm that manages its capital stock, may issue equity and debt, and may hold financial assets. We can write this budget constraints as

$$
s_{t} d_{t}+q_{t}\left(a_{t+1}-a_{t}\right)+x_{t} \leq \pi_{t}\left(k_{t}, l_{t}\right)+a_{t} e_{t}-r_{t} b_{t}+b_{t+1}-b_{t}+p_{t}\left(s_{t+1}-s_{t}\right)
$$

where $s$ represents the stock of outstanding equity shares which have price $p, d$ represents dividends paid per share, $a$ is the stock of the firm's financial assets which have price $q$ and pay period $t$ dividends $e, x$ is physical investment, $\pi$ is gross profit of the firm (net of factor payments and taxes), $r$ is the net interest rate on debt $b$. We rearrange this express as

$$
s_{t} d_{t}+q_{t}\left(a_{t+1}-a_{t}\right)-\left(b_{t+1}-b_{t}\right)-p_{t}\left(s_{t+1}-s_{t}\right) \leq \pi_{t}\left(k_{t}, l_{t}\right)+a_{t} e_{t}-r_{t} b_{t}-x_{t} .
$$

The left hand side of equation (1) represents the net financial flow into or out of the firm. If the right hand side of equation (1) is positive so that the firm's investment is less than the cash generated by the firm in period $t$, then funds flow out of the firm. If the right hand side of equation (1) is negative, then funds must flow into the firm as the firm's investment is greater than the cash it generated. Implicitly, by netting interest payments, $r_{t} b_{t}$, out of available funds, but leaving dividend payments, $s_{t} d_{t}$, on the left hand side, we assume that dividends are not set in advance while interest payments cannot be re-negotiated.

Our aim, then, is to measure available funds defined as

$$
A F_{t}=\pi_{t}+a_{t} e_{t}-r_{t} b_{t}
$$


and physical investment, $x_{t}$, as these measures are sufficient to determine whether a given firm receives inflows of cash or makes cash outlays.

Our preferred statistic of how individual firms rely on external funds for investment is given by

$$
\frac{1}{T} \sum_{t=1}^{T} \frac{\sum_{i}\left(X_{i t}-A F_{i t}\right) \mathbf{1}_{\left[X_{i t} \geq A F_{i t}\right]}}{\sum_{i} X_{i t}}
$$

The statistic in equation (2) represents the average net financial inflow to firms whose investment is greater than their available funds as a fraction of total investment. The statistic in equation (1) informs us about what fraction of aggregate investment must be financed externally among a subset of firms, and, therefore, depends on well-functioning financial markets.

\subsection{Data Description}

Our data sources for the U.S. include the Flow of Funds, the Statistics of Income, and Compustat. Our data sources for the U.K. include the U.K. Economic Accounts, Compustat Global, and Amadeus. We now describe each data set and how we measure available funds and investment in each source.

\subsubsection{U.S. Data}

Aggregate Data. Aggregate U.S. data are from the Flow of Funds. Our measure of aggregate available funds in the U.S. is the sum of Internal Funds (Table F.102 line 9) and Dividends (Table F.201 line 3) of all non-farm nonfinancial corporate business. Note that we add dividends here because the definition of Internal Funds has excluded them. Our measure of aggregate investment is given by Capital Expenditures (Table F.102 line 11) of non-farm nonfinancial corporate businesses.

Our second source of aggregate data is the Statistics of Income, specifically the Corporation Income Tax Returns, from 1991 to 2008. The Corporation Income Tax Returns data set contains information on assets, liabilities, and income of all incorporated firms in the U.S. classified by industry and by size of total assets. We focus on data classified by size of total assets, specifically Table 2, which details the balance sheet and income statement of active corporations. The advantage of using data from the Statistics of Income is that we can analyze aggregate financial flows to firms of various sizes. In other words, we can analyze whether the average small firm receives financial inflows even though in the aggregate all firms make financial outflows. There are three limitations to working with data from the Statistics of Income. The first is that the data cover all active corporations in the United 
States, including agricultural and financial firms. The second limitation is that data are not firm-level, so we can only analyze the net financial flows to an aggregated small firm. The final limitation is that the size classes for the data are presented in nominal terms which can introduce measurement bias (due to inflation and trend growth) as discussed in Gertler and Gilchrist (1994).

In any year, an observation in this data set represents the aggregate over all firms with assets within some nominal bounds. We measure available funds as total receipts less total deductions plus deductions for depreciation, depletion, and amortization. To measure investment, we must construct a measure of the change in fixed assets from one year to the next. Our measure of fixed assets in any year is the sum of depreciable assets, depletable assets, intangible assets, and land less accumulated depreciation, depletion, and amortization. To measure fixed asset growth among firms in any size class, we must make an educated guess about how firms move across size classes from one year to the next. Our analysis parallels that of Gertler and Gilchrist (1994). First, we re-aggregate the size categories into two groups for "small" and "large." Our cutoff for small firms is the threshold in assets below which firms account for 30 percent of sales. The annual growth rate of assets for small firms, then, is a weighted average of the growth rate of the cumulative asset classes on either side of the thirtieth percentile at the start of the period. We then make adjustments to the growth rate to correct for bias introduced by the fact that some firms may have shifted asset classes. We also perform this procedure to construct a measure of the change in accumulated depreciation, depletion, and amortization, which we then use as our measure of depreciation over the year. Our measure of investment for small firms, then, is given by the growth in fixed assets plus depreciation. Investment for large firms is constructed similarly.

Firm Level Data. Our primary source of firm-level data in the U.S. is Compustat. Compustat provides financial data on firms actively traded on stock exchanges. We focus on data from 1974 to 2010. We restrict attention to firms headquartered in the U.S. (location code is USA) and we omit firms in Financial, Real Estate and Insurance industries (SIC codes 60-67) and Government (SIC codes 91-99).

We construct available funds and investment for firms in Compustat as in the literature on firm dependence on external financing (see Rajan and Zingales (1998)). In particular, we measure available funds for a firm $i$ in period $t$, as Operating Activities - Net Cash Flow (or Funds from operations depending format of the statement of cash flows). Because our model does not distinguish between physical investment in existing assets or acquisition of new assets, we wish to include merger and acquisition activity as well as sales of property, plant and equipment (as negative investment) in our measure of investment. We define investment as the sum of capital expenditures and acquisition less sale of property plant and equipment. 
Firms remain in our sample if we have sufficient data to construct our measures of available funds and investment. We also require firms to have reported positive sales and non-negative total liabilities. Our Compustat sample in the U.S. consists of about 51,000 firm-year observations, with roughly 1400 firm level observations in a typical year.

\subsubsection{U.K. Data}

Aggregate Data. Our source of aggregate data in the U.K. is the National Economic Accounts. We measure available funds as the sum of gross disposable income and dividends of non-financial corporations. Again, we add dividend payments back in because they have been previously excluded in the construction of gross disposable income. We measure investment as the sum of gross fixed capital formation, change in inventories, and acquisitions less disposals of valuables and non-financial non-produced assets.

Firm Level Data. We have two sources of panel data on financial statements of firms in the U.K. Our first data source is Compustat Global and only covers firms that are actively traded on a stock exchange. We treat data from Compustat Global exactly as we do for data from Compustat U.S.. Compustat U.K. sample consists of roughly 10,000 firm-year observations between 1992 and 2009, with 550 firm level observations in a typical year.

Our primary source of firm level data for firms not actively traded on a stock exchange is Amadeus. Amadeus contains financial information on over 18 millions private and public companies in Europe with a focus on private companies. We restrict attention to the sample of firms located in the United Kingdom from 2001 to 2009. We focus on data from the balance sheet and profit and loss account. Data limitations prevent us from measuring available funds and investment as we do in our Compustat sample, but we attempt to be as consistent as the data allow us. Specifically, we measure available funds as the sum of profit (loss) for period, which is roughly equivalent to income before extraordinary items, and depreciation. We measure investment as the change in tangible assets plus depreciation. ${ }^{2}$ While we focus on the privately held sample of firms in Amadeus, we also report statistics for the publicly traded firms that are available to provide a comparison to the more comprehensive sample of publicly traded firms from Compustat Global. ${ }^{3}$

\footnotetext{
${ }^{2}$ We have also measured investment by additionally including intangible assets, but this addition had negligible effects on our measure of external financing.

${ }^{3}$ We have also measured available funds and investment in this manner for both of our Compustat samples. We found that this measure of investment is roughly consistent with our measure of investment from Compustat, while this measure of available funds tends to understate the amount stated as Operating Activities - Net Cash Flow. The primary discrepancy between these measures of available funds arises from the treatment of unclassified funds. To the extent that income before extraordinary items and depreciation listed on the income statement of firms in Amadeus and Compustat are measured comparably, this finding suggests that our measure of Available Funds in Amadeus may be biased downward, and thus our measure
} 
Our sample of privately held firms consists of all non-government, non-financial firms whose legal status is Private Limited Company or Public Limited Company and which are not quoted on a stock exchange. We also restrict attention to firms that report non-negative total liabilities (defined as the sum of current and non-current liabilities), non-negative total assets, and non-negative sales. Because one component of our measure of investment is the change in tangible assets, we must have at least two consecutive years of data for a firm to remain in our sample. Our sample consists of over 980,000 firm-year observations with roughly 100,000 firm-level observations in each year. Our Amadeus sample of Public Limited Companies that are quoted on a stock exchange consists of roughly 3700 firm-year observations with 400 firm-level observations in a typical year.

\subsection{Facts about Financial Flows and External Financing}

We now describe the facts on financial flows and external financing. We begin by describing the lessons from aggregate or aggregated data, and then discuss the evidence on firm-level dependence on external financing.

\subsubsection{Aggregate Facts on Financial Flows}

In figures 3 and 5 we plot available funds and investment for the U.S. and the U.K normalized by nonfinancial corporate business GDP (in the U.S.) and by aggregate GDP (in the U.K.). On average, available funds are roughly 1.25 times as large as investment in the U.S. and 1.9 times as large in the U.K. Moreover, in the U.S. available funds exceed investment by roughly $3 \%$ on average over the entire sample. In this sense, the aggregate firm in the U.S. and the U.K. does not rely on outside financing to fund investment.

We have argued that this observation presents a challenge for macroeconomics models with a representative firm that faces a binding collateral constraint. There are two primary responses to this challenge. First, to the extent that shareholders refuse to accept delayed dividend payments, firms may not be able to self-finance their investment using available funds net of dividends. In figures 4 and 6 we plot internal funds, or available funds net of dividends, and investment in the U.S. and in the U.K. This data shows that internal funds are on average roughly $95 \%$ of investment in the U.S. (though they are still 1.35 times as large as investment in the U.K.). Representative agent models of financial frictions, then, must rely on some mechanism to ensure that dividends in the aggregate do not respond to aggregate shocks. In our model, because dividends of privately held firms are simply consumption of of external financing in Amadeus may be biased upwards. 
the undiversified owners of the firm, standard consumption smoothing motives will cause dividends to not adjust to aggregate shocks.

The second response to the fact that available funds exceed investment in the aggregate is that the aggregate statistics do not reveal information about how much individual firms rely on external financing. The Statistics of Income data, by reporting data by asset size classes, yields information on whether there different size classes of firms rely on external financing. We find, however, that even small firms, in the aggregate, have sufficient available funds to finance their investment. From 1992 to 2008, on average, available funds for large firms are roughly 1.8 times as large as investment, and for small firms, available funds are roughly 4 times as large as investment. We conclude that it is necessary to look at firm-level evidence in order to gauge which firms rely on external financing and how much external financing these firms need for investment.

\subsubsection{Firm Level Evidence on External Financing}

In this section, we provide evidence on the importance of external financing in firm level data. In Compustat in the U.S.. we find that on average roughly $23 \%$ of investment undertaken by publicly held firms is financed externally. Similarly, in the U.K., we find that roughly $20 \%$ of investment by publicly held firms is financed externally. ${ }^{4}$

Analyzing U.K. data for privately held firms, we find that between $70 \%$ and $95 \%$ of aggregate (Amadeus) investment is financed externally from 2001-2008. We provide a range of estimates because our measure of external financing is sensitive to different treatments of potential outliers. On the entire sample, we find that roughly $95 \%$ of investment is externally finance. If we remove the three largest and smallest observations over the entire sample, then we find that roughly $90 \%$ of investment is externally financed. When we winsorize the sample at the $0.1 \%$ and $99.9 \%$ levels, removing observations in the smallest 0.1 percentile and largest 99.9 percentile of available funds and investment, we find that roughly $85 \%$ of investment is externally financed; winsorizing at the 1 and 99 percentiles yields that on average $70 \%$ of investment is externally financed.

It is possible that our splitting of data by privately and publicly held firms is merely serving as a proxy for firm size. To address this issue, we construct a sample of privately held and publicly traded firms of approximately the same size over the same horizon (20012009). Specifically, we begin by following Gertler and Gilchrist (1994) to develop a sample of "large" privately held firms. In any year, we classify a firm in our Amadeus sample as "large" if its assets are over a threshold above which firms account for $70 \%$ of (Amadeus)

\footnotetext{
${ }^{4}$ This average excludes the year 1999 because of a lack of data availability for acquisitions. Alternatively, if we ignore acquisitions, then over the entire sample, roughly $8 \%$ of investment is externally financed.
} 
sales. We then construct a sample of "small" publicly held firms in the U.K. similarly, except we classify a firm as "small" if its assets are below the threshold in which firms account for $30 \%$ of (Compustat) sales.

Our sample of small publicly traded firms consists of roughly 6700 firm year observations with firms holding on average $£ 184$ million in total assets (with a standard deviation of $£ 3.75$ billion). Our sample of large privately held firms consists of roughly 18000 firms with assets of roughly $£ 840$ million on average with a comparable standard deviation (roughly $£ 3.6$ billion). Notice that our large, privately held firms are on average larger than our small, publicly traded firms. Of course, the small publicly traded sample comprises the majority of the data in our overall Compustat UK sample, while the large privately held sample comprises roughly $2 \%$ of our Amadeus sample.

It is not surprising then that our sample of small publicly traded firms externally finance roughly $21 \%$ of their investment. However, even after cleaning the large sample of the most extreme values of investment and available funds, we find that large privately held firms externally finance roughly $90 \%$ of their investment (small privately held firms externally finance an even larger fraction of their investment - roughly 110\%). Our conclusion is that privately held firms externally finance a substantially larger fraction of their investment than do publicly traded firms. As a result, we expect privately held firms to be much more sensitive to exogenous changes in financing conditions than publicly held firms.

\section{A Dynamic Model of Publicly Traded and Privately Held Firms}

In this section, we develop a dynamic model of publicly traded and privately held firms and define a symmetric stationary equilibrium. In our model, all firms face constraints in accumulating capital, have a monopoly in producing differentiated goods and require a bundle of goods produced by other firms as an input to production. Publicly held firms are owned by diversified households; privately held firms are owned by individual entrepreneurs.

\subsection{Model and Equilibrium Definition}

Environment. Time is discrete, lasts forever, and is indexed by $t=1,2, \ldots$ Agents in the model include households, final good producers, and intermediate good producers. There is a single consumption good in the economy which is a composite good produced by a sector of competitive final good producers. We normalize the price of the final good to be 1 in each period. Final good producers aggregate the output of the intermediate good producers. 
Each intermediate good producer has a monopoly in producing a differentiated output. There are two classes of intermediate good producers: privately-held and publicly-held firms. We normalize the total measure of intermediate good producing firms to be 1 , and we assume there is a fixed measure of privately held firms, s. A firm's type is exogenously given and fixed for the lifetime of the firm. Let firms $i \in[0, s]$ denote the names of the $s$ privately held firms and $i \in[s, 1]$ denote the names of the $1-s$ publicly held firms in any period. Firms exogenously exit at rate $1-\zeta$. Upon exit, firms are replaced by an otherwise identical firm endowed with the exiting firm's assets.

In our model, we distinguish between publicly and privately held firms by assuming that publicly held firms are owned by and rebate dividends to diversified households. Privately held firms are owned by individual entrepreneurs for whom the cost of delayed dividend payments is forgone consumption.

In each period, a firm of either type can produce a output according to the constant returns to scale production function

$$
y_{i t}=z_{i t}^{\frac{1}{\rho-1}}\left(k_{i t}^{\alpha} l_{i t}^{1-\alpha}\right)^{\eta} I_{i t}^{1-\eta}
$$

where $z_{i t}, k_{i t}, l_{i t}, I_{i t}$ are firm $i$ 's productivity, capital input, labor input, and intermediate good input in period $t$ respectively, and $\rho$ represents the elasticity of substitution across all goods. The intermediate input is a composite of the output of every other intermediate good firm:

$$
I_{i t}=\left(\int_{0}^{1} I_{i t k}^{1-\frac{1}{\phi}} d k\right)^{\frac{\phi}{\phi-1}} .
$$

For simplicity, we assume that the elasticity of substitution for firms' inputs and households' consumption are the same, i.e. $\phi=\rho$ (see Basu (1995) for an example of this type of inputoutput production structure). We assume that the firm-level process for productivity follows the stochastic process $\Psi\left(z_{i t} \mid z^{i t-1}\right)$ where $z^{i t-1}$ represents the history of productivity shocks that firm $i$ has received from it's initial period to period $t-1$.

We assume that labor markets are competitive and both types of firms have access to competitive financial intermediaries who receive deposits and rent capital at rate $R_{t}$ to firms. We assume that lending to firms is not perfectly enforceable. After production, firms can choose to default on their loan from the financial intermediary and, with probability $1 / \lambda$ they are able to retain their undepreciated capital stock (isomorphically, they are able to retain a fraction $1 / \lambda$ of their undepreciated capital). If a firm defaults, the financial intermediary seizes the financial wealth of the firm, but the loss of financial wealth is the only punishment firms face from defaulting on their debt obligations. The zero-profit condition for financial 


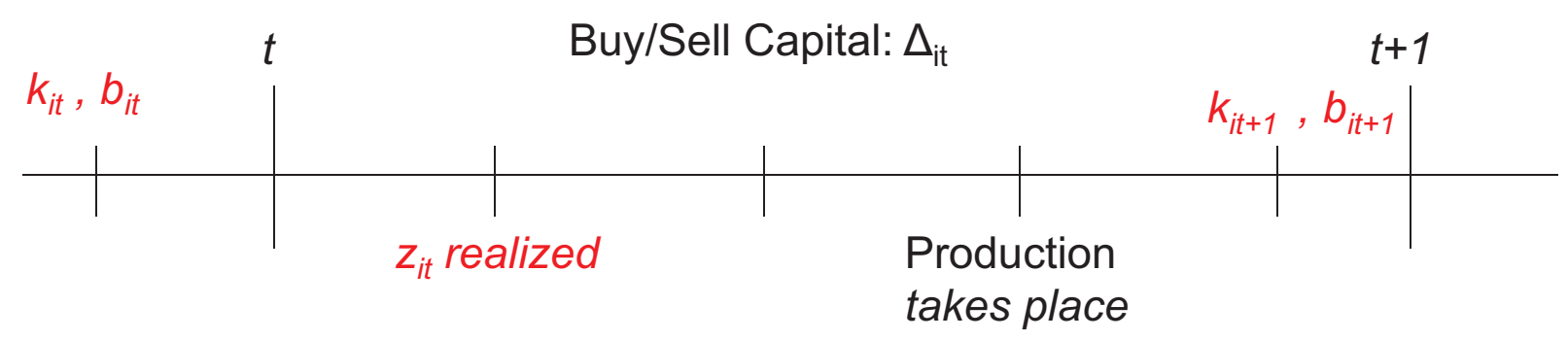

Figure 1: Timing of Production and Financing

intermediaries implies that the capital rental rate is given by $r_{t}+\delta$.

We now describe the problem and constraints of each type of agent in turn.

Final Good Producers. There are a large number of competitive final good producers. Each of these producers can combine the output of the intermediate producers to produce a composite final good according to the production function

$$
Q_{t}=\left[\int_{i} q_{i t}^{1-\frac{1}{\rho}} d i\right]^{\frac{\rho}{\rho-1}}
$$

where $q_{i t}$ is the input of firm $i$ in period $t$, and $\rho$ is the elasticity of substitution across all goods in the economy. Perfect competition among final good producers ensures that we can focus on a representative firm that solves

$$
\max _{Q, q_{j i}} Q-\int_{i} p_{i t} q_{i t} d i
$$

subject to the $Q$ is given by the production function in (3) in each period. As before, the final good producer's problem gives rise to an inverse demand curve for each intermediate good as a function of prices:

$$
p_{i}=Q_{t}^{\frac{1}{\rho}} q_{i t}^{\frac{-1}{\rho}} .
$$

Finacing and Timing of Production. Here we describe the timing of production by intermediate good firms and its interaction with firms' financing decision. Throughout, we assume that there is no equity financing. This assumption does not have any effect on production decisions of publicly held firms. Figure 3.1, describe the timing of financing and production decision of the intermediate good firms. 
As it is shown, consider a firm that enters period $t$ with capital stock $k_{i t}$ and debt $b_{i t}$ determined at $t-1$. The owner/owners of the firm, learn about the productivity shock at $t, z_{i t}$. Upon learning its productivity, the firm can adjust its capital stock by issuing debt. This adjustment to capital stock is subject to a collateral constraint:

$$
b_{i t}+\Delta_{i t} \leq \frac{\lambda-1}{\lambda}\left(k_{i t}+\Delta_{i t}\right)
$$

The firm, then, hires labor and purchases intermediate inputs in order and production takes place. Once production has taken place, the firm decides on how much new debt to issue as well as how much to invest. Hence, the budget constraint for this firm can be written as

$$
\begin{aligned}
d_{i t}+x_{i t} \leq & p_{i t} z_{i t}\left[\left(k_{i t}+\Delta_{i t}\right)^{\alpha} l_{i t}^{1-\alpha}\right]^{\eta} I_{i t}^{1-\eta}-I_{i t}-w_{t} l_{i t} \\
& +\left(b_{i t+1}-b_{i t}-\Delta_{i t}\right)-r_{t}\left(b_{i t}+\Delta_{i t}\right)
\end{aligned}
$$

Note that there are two types of investment taking place in period $t, \Delta_{i t}$ and $x_{i t}$. Since $\Delta_{i t}$ is being used in production in that period, it is subject to depreciation while $x_{i t}$ is not. Hence, the end of period $t$, capital stock for the firm is given by

$$
k_{i, t+1}=x_{i t}+\left(k_{i t}+\Delta_{i t}\right)(1-\delta)
$$

The above assumtion about production and financing, helps us significantly simplify the problem. In particular, it is easy to see that we do not need to keep track of $k_{i t}, b_{i t}$ jointly and the only state variable other than productivity is net worth or $a_{i t}=k_{i t}-b_{i t}$.

Privately Held Firms. We assume that privately held firms face incomplete markets. Specifically, we assume that ownership of the privately held firms are concentrated and that they cannot issue any equity. We assume that the owners of privately held firms that are born in period $j$ have the following preferences

$$
E_{j} \sum_{t \geq j}(\beta \zeta)^{t-j} \log \left(d_{i t}\right) .
$$

We assume that in making their production and financing choices, the owners of privately held firms are subject to the budget constraint described in (5), the collateral constraint (4), and the inverse demand for their production.

Publicly Held Intermediate Good Producers. As stated above, publicly held firms have 
the same production opportunities as a privately held firms. The only difference between publicly held firms and privately held firms arises from differences in ownership. Because publicly held firms are owned by diversified households, they maximize the expected present discounted value of their dividends under the stochastic discount factor of the households, which, in the economy with no aggregate risk is simply $\beta^{t}$. The objective of a publicly held firm is given by the expected present discounted value of dividends, or

$$
E_{0} \sum_{t} \beta^{t} d_{i t}
$$

Similar to privately held firms, the owners of the publicly held firms are subject to a budget constraint, collateral constraint and inverse demand. Furthermore, we assume that they cannot issue any equity, i.e., $d_{i t} \geq 0$.

Bankruptcy and Entry. As it is clear above, public and private firms have different discount factor. We interpret this as uninsurable bankruptcy by privately held firms. That is we assume that every period, privately held firms becom bankrupt with probably $1-$ $\zeta$. Furthermore, in each period an equal measure of firms are borne and draw assets and productivities from the joint stationary distribution of assets and productivities. That is we assume that there are no losses in the value of the assets from bankruptcy. Later we perform robustness on this assumption and assume that newly born firms assets are a fraction of th amount of assets in the economy.

Households. In each period, households decide how much to work, how much to consume and how much to save in the risk-free bond. They maximize lifetime expected utility

$$
E_{0} \sum_{t} \beta^{t} U\left(C_{h t}, L_{h t}\right)
$$

subject to the sequence of budget constraints

$$
C_{h t}+A_{t+1}^{h} \leq w_{t} L_{h t}+\left(1+r_{t}\right) A_{t}^{h}+\int_{s}^{1} c_{i t} d i .
$$

Equilibrium Definition. The aggregate state of the economy in any period can be summarized by the distributions over debt, $b$, capital stock, $a$, and productivity, $z$, of privately held firms which we denote by $G_{u}(b, k, z)$, of publicly held firms which we denote by $G_{l}(b, k, z)$ and household assets $A^{h 5}$. In a stationary equilibrium, we can summarize the market clearing

\footnotetext{
${ }^{5}$ Notice that given our assumptions about the timing of production and financing, net worth or $k-b$ is
} 
constraints using these distributions and the decisions made by privately held and publicly held firms as functions of their individual states. We have four market clearing constraints. Bond market clearing is given by

$$
\sum_{i=l, u} n_{i} \int_{a, z}\left[b_{i}(b, k, z)+\Delta_{i}(b, k, z)\right] G_{i}(d b, d k, d z)=A^{h}
$$

where $n_{i}$ represents the measure of type $i$ firms and $b_{i}(b, k, z)+\Delta_{i}(b, k, z)$ is the amount of debt issued by a firm of type $i$ (either publicly or privately held) with individual state $b, k, z$, and $A^{h}$ represents asset holdings of households. The market clearing constraint for final goods is given by

$$
C_{h}+n_{u} \int_{a, z} d_{u}(b, k, z) G_{u}(d b, d k, d z)+K^{\prime}-(1-\delta) K=Q-\sum_{i=l, u} n_{i} \int_{a, z} I_{i}(a, z) G_{i}(d a, d z)
$$

where $K$ is the aggregate capital stock given by

$$
K=\sum_{i=l, u} n_{i} \int_{a, z}\left[k_{i}(b, k, z)+\Delta_{i}(b, k, z)\right] G_{i}(d b, d k, d z)
$$

Intermediate goods market clearing requires for each $i=l, u$

$$
q_{i}(b, k, z)=z^{\frac{1}{\rho-1}}\left(k_{i}(b, k, z)^{\alpha} l_{i}(b, k, z)^{1-\alpha}\right)^{\eta} I_{i}(b, k, z)^{1-\eta}
$$

and labor market clearing requires

$$
L_{h}=\sum_{i=l, u} n_{i} \int_{a, z} l_{i}(b, k, z) G_{i}(d b, d k, d z) .
$$

Finally, a stationary equilibrium entails that $G_{i}$ is stationary for $i=l, u$, or for any $\mathcal{B}, \mathcal{K}$ and $\mathcal{Z}$

$$
\begin{aligned}
G_{i}(\mathcal{B}, \mathcal{K}, \mathcal{Z}) & =\int_{a, z} Q_{i}((b, k, z), \mathcal{B} \times \mathcal{K} \times \mathcal{Z}) G_{i}(d b, d k, d z) \\
Q_{i}((b, k, z), \mathcal{B} \times \mathcal{K} \times \mathcal{Z}) & =\int_{z} \mathbf{1}\left\{b_{i}^{\prime}(b, k, z) \in \mathcal{B}\right\} \mathbf{1}\left\{b_{i}^{\prime}(b, k, z) \in \mathcal{K}\right\} \psi(z) d z
\end{aligned}
$$

where $\psi(z)$ represents the stationary distribution over idiosyncratic productivity and, in addition, household savings is stationary, or $A^{\prime h}=A^{h}$.

a sufficient state variable and one need not keep track of both $b$ and $k$. In other words, the distribution function $G_{u}$ and $G_{l}$ are only a function of $k-b$. 
Definition 1. A stationary recursive competitive equilibrium consists of prices, $p_{i}(b, k, z), r, w$, aggregate output $Q$, distributions $G_{l}, G_{u}$, value functions $V_{l}, V_{u}$, policy functions for firms $\left(d_{i}(b, k, z), b_{i}^{\prime}(b, k, z), k_{i}^{\prime}(b, k, z), l_{i}(b, k, z), I_{i}(b, k, z)\right)_{i \in l, u}$, policy functions for households, $C_{h}\left(A^{h}\right), L_{h}\left(A^{h}\right), A^{\prime}$ such that

1. Given aggregate output, the wage, the interest rate, and the inverse demand curve of the final good producer, $\left(c_{u}(b, k, z), b_{u}^{\prime}(b, k, z), k_{u}^{\prime}(b, k, z), l_{u}(b, k, z)\right)$ solves the problem of a privately held firm given by

$$
\begin{aligned}
V_{u}(b, k, z)= & \max _{\begin{array}{l}
d, b^{\prime}, k^{\prime}, l, I, x, \Delta \\
\text { subject to }
\end{array}} \log (d)+\beta \zeta \int_{z^{\prime}} V_{u}\left(b^{\prime}, k^{\prime}, z^{\prime}\right) d \Psi\left(z^{\prime} \mid z\right) \\
d+x \leq & p_{i}(b, k, z) z^{\frac{1}{\rho-1}}\left((k+\Delta)^{\alpha} l^{1-\alpha}\right)^{\eta} I^{1-\eta}-w l-I \\
& +\left(b^{\prime}-b-\Delta\right)-r(b+\Delta)(1+r) a \\
b+\Delta \leq & \frac{\lambda-1}{\lambda}(k+\Delta) \\
k^{\prime}= & (k+\Delta)(1-\delta)+x \\
p_{i}(b, k, z)= & Q^{\frac{1}{\rho}}\left(z^{\frac{1}{\rho-1}}\left((k+\Delta)^{\alpha} l^{1-\alpha}\right)^{\eta} I^{1-\eta}\right)^{-\frac{1}{\rho}}
\end{aligned}
$$

2. Given aggregate output, the wage, the interest rate, and the inverse demand curve of the final good producer, $\left(d_{l}(b, k, z), b_{l}^{\prime}(b, k, z), k_{l}^{\prime}(b, k, z), l_{l}(b, k, z), I_{l}(b, k, z)\right)$ solves the problem of a publicly held firm given by

$$
\begin{aligned}
V_{l}(b, k, z)= & \max _{\substack{d, b^{\prime}, k^{\prime}, l, I, x, \Delta \\
\text { subject to }}} d+\beta E_{z^{\prime}} V_{l}\left(b^{\prime}, k^{\prime}, z^{\prime}\right) \\
d+x \leq & p_{i}(b, k, z) z^{\frac{1}{\rho-1}}\left((k+\Delta)^{\alpha} l^{1-\alpha}\right)^{\eta} I^{1-\eta}-w l-I \\
& +\left(b^{\prime}-b-\Delta\right)-r(b+\Delta)(1+r) a \\
b+\Delta \leq & \frac{\lambda-1}{\lambda}(k+\Delta) \\
k^{\prime}= & (k+\Delta)(1-\delta)+x \\
p_{i}(a, z)= & Q^{\frac{1}{\rho}}\left(z^{\frac{1}{\rho-1}}\left(k^{\alpha} l^{1-\alpha}\right)^{\eta} I^{1-\eta}\right)^{-\frac{1}{\rho}}
\end{aligned}
$$

3. Given the policy functions of publicly and privately held firms, the value functions $V_{u}$ and $V_{l}$ satisfy (10) and (13)

4. Given dividend payments of publicly held firms and the wage rate, household consump- 
tion and labor solve

$$
\begin{aligned}
& \max U\left(C_{h}, L_{h}\right) \\
& \text { subject to } \\
C_{h}= & w L_{h}+(1-s) \int d(b, k, z) G_{l}(d b, d k, d z)
\end{aligned}
$$

5. The market clearing conditions (??), (8), (9) hold,

6. $G_{l}$ and $G_{u}$ satisfy the stationarity conditions.

In Appendix C:, we provide a partial characterization of the optimal decision rules of firms. By choosing to model all debt as intra-period, the optimal capital and labor decisions are purely static. As a result, the problem of a privately held firm can be simplified by two-stage budgeting. In any period, the firm chooses capital and labor; after making these decisions, the firm then decides how much to consume and save. The reaming consumptionsavings decision is essentially the same as the one studied in Huggett (1993) or Aiyagari (1994). The key difference from those models is that savings affects future profits of the firm by potentially relaxing the collateral constraint in future periods.

Before discussing theoretical and quantitative results from our model, we find it useful to demonstrate how we compute external financing in the model. Mechanically, we think of the model as generating balance sheet and income statement data and analyze the data from the model exactly as we do in the data. To see this process, let us rewrite the budget constraint in terms of $\hat{k}_{t}=k_{t}+\Delta_{t}$ and $\hat{b}_{t}=b_{t}+\Delta_{t}$, the within period capital and debt. With this notation, the budget constraint of the firm is given by

$$
d_{t}+x_{t}=p_{t} y_{t}\left(z_{t}, \hat{k}_{t}, l_{t}\right)-w l_{t}-I_{t}+b_{t+1}-\hat{b}_{t}-r_{t} \hat{b}_{t}
$$

or, adding $\Delta_{t+1}$ to both sides

$$
d_{t}+X_{t}=p_{t} y_{t}\left(z_{t}, \hat{k}_{t}, l_{t}\right)-w l_{t}-I_{t}+\hat{b}_{t+1}-\hat{b}_{t}-r_{t} \hat{b}_{t}
$$

At this point, we can define available funds and investment as we do in the data. We have

$$
\begin{aligned}
A F_{t} & =p_{t} y_{t}-w_{t} l_{t}-I_{t}-r_{t} b_{t} \\
X_{t} & =\hat{k}_{t+1}-(1-\delta) \hat{k}_{t}=x_{t}+\Delta_{t+1}
\end{aligned}
$$

Since the state at $t$ is given by $b_{t}, k_{t}, z_{t}$, we may define investment $X_{t}$ as a function only of $b_{t}, k_{t}, z_{t}$, and $z_{t+1}$. We can then define external financing in the model exactly as in the data 
(with a slight abuse of notation defining the distribution over $b, k, z, z^{\prime}$ ):

$$
\frac{\int_{b, k, z, z^{\prime}}\left(X_{t}\left(b, k, z, z^{\prime}\right)-A F_{t}(b, k, z)\right) \mathbf{1}_{\left[X_{t} \geq A F_{t}\right]} d H\left(b, k, z, z^{\prime}\right)}{\int_{b, k, z, z^{\prime}} X_{t}\left(b, k, z, z^{\prime}\right) d H\left(b, k, z, z^{\prime}\right)} .
$$

\subsection{Theoretical Results}

In this section, we describe theoretical results that shed light on how the collateral constraints affect publicly held firms, the general equilibrium effects that arise in our model due to differentiated goods and the input-output structure of productions, and how the responsiveness of the economy to collateral constraint shocks depends on how much external financing occurs in the steady state equilibrium. Throughout this section, we denote net worth by $a_{t}=k_{t}-b_{t}$ and note that the set of constraints the firms are facing becomes

$$
\begin{aligned}
d_{t}+a_{t+1} & =p_{t} y_{t}-w_{t} l_{t}-\left(r_{t}+\delta\right) \hat{k}_{t}+\left(1+r_{t}\right) a_{t} \\
k_{t} & \leq \lambda a_{t}
\end{aligned}
$$

In this section, we use the above formulation for simplicty of exposition.

\subsubsection{Equilibrium External Financing by Publicly Held Firms}

In this section, we argue that because publicly held firms discount at the same rate as household, in any equilibrium in which household consumption is stationary, publicly held firms never face binding collateral constraints. To see this. consider the problem faced by publicly held firms. If the non-negative dividend constraint or the collateral constraint ever bind along any future history with positive probability, then the value of funds inside the firm are worth more than the value of funds outside the firm. This result combined with the fact that publicly held firms are risk neutral implies that in any such period, dividends in that period must be zero. We state this result as the following lemma (the proof is in Appendix C:).

Lemma 2. In any period $t$, if either the non-negative dividend constraint or the collateral constraint in any history $z^{s}$ with $s \geq t$ then dividends in period $t$ are zero.

The consequence of this lemma is that as long as either of a publicly held firm's constraints bind, the firm's asset level increases. To see this, note that stationarity of household consumption implies that $\beta(1+r)=1$ and thus $1+r>1$. The budget equation of a publicly held firm with zero dividends implies

$$
a_{t+1}=\Pi\left(a_{t}, z_{t}\right)+(1+r) a_{t}>a_{t}
$$


since profits are (weakly) positive and the interest rate is positive. Of course, as long as $z_{t} \in[\underline{z}, \bar{z}]$ then there is a maximal optimal scale for the firm. Call this value $\bar{k}$. Once the publicly held firm's assets satisfy $a_{t} \geq \frac{1}{\lambda} \bar{k}$ then the firm can simply save $a_{t}$ in every future period, rebate any profits and interest income to households in the form of dividends and never face binding constraints again. Since the firm's assets grow monotonically, they must cross this threshold. As a result, in any stationary equilibrium, each publicly traded firm's assets must lie above $\frac{1}{\lambda} \bar{k}$. We then have the following proposition.

Proposition 3. In any stationary equilibrium, the collateral constraint never binds for any publicly held firm.

An immediate consequence of the proposition is that there are a continuum of equilibria indexed by asset holdings of publicly held firms above $\frac{1}{\lambda} \bar{k}$ and a corresponding asset holding of households so that capital markets clear at the given rental rate of capital, $r=\frac{1}{\beta}-1$. Since available funds for a given firm satisfy

$$
A F_{t}=p_{t} y_{t}-w_{t} l_{t}-r_{t}\left(k_{t}-a_{t}\right)
$$

publicly traded firms in stationary equilibria always operate at optimal scale, we have $A F_{t}=$ $\Pi^{*}\left(z_{t}\right)+r_{t} a_{t}$. Since there is an equilibrium for any $\bar{a} \geq \frac{1}{\lambda} \bar{k}$, available funds are indeterminate. Consequently, the amount of external funds used by publicly held firms for investment is indeterminate. We state this result as the following corollary.

Corollary 4. In any stationary equilibrium, the amount of external funds used by publicly held firms to finance investment is indeterminate.

\subsubsection{The Effects of Collateral Shocks on Unconstrained Firms}

In any period in any stationary equilibrium of our model, some firms face binding collateral constraints and others do not. Some of the firms that do not face binding constraints are publicly held and others are privately held. One consequence of a shock that leads to a tightening of the collateral constraint is that firms that do not face currently binding collateral constraints become more productive relative to those firms for whom the collateral constraint binds. As a result, these firms, absent any general equilibrium effects, would increase their demand for production inputs and generate more output. This mechanism dampens the effects of shocks to the collateral constraints.

We argue that general equilibrium effects cause shocks to the collateral constraints to spill-over to these unconstrained firms and can dampen and even overturn their incentives to increase production in response to a tightening of the constraints. In Appendix A:, we analyze 
a static, partial equilibrium version of our model where households value consumption and labor according to

$$
U(C, L)=u\left(C-\frac{\psi}{1+\frac{1}{\varepsilon}} L^{1+\frac{1}{\varepsilon}}\right)
$$

as in Greenwood et al. (1988). We develop sufficient conditions for the equilibrium output of every firm to be decreasing in the tightness of the collateral constraints. The key parameters that determine the strength of these general equilibrium spill-overs are the elasticity of household labor supply, $\varepsilon$, the elasticity of substitution across goods, $\rho$, the labor share parameter, $\alpha$, and the intermediate input share parameter, $\eta$. We now state our main result from Appendix A:.

Proposition 5. Suppose there exists a positive measure set of constrained firms. If $1+\varepsilon \geq$ $\eta \rho(1-\alpha)$, then output of all firms is increasing in the collateral constraint parameter, $\lambda$.

The intuition for this result follows our argument in the introduction. A tightening of the collateral constraint causes constrained firms to reduce their demand for capital. Since capital and labor are complements in production, constrained firms also decrease their demand for labor. The decrease in the demand for labor causes the wage rate to fall. The decline in the wage leads to a decline in demand for the final good. Our functional form assumptions on the production function and household preferences then imply the result in the proposition. The elasticity of output of an unconstrained firm with respect to the wage rate, under the Cobb-Douglas form of the production function that we have assumed is simply $\eta \rho(1-\alpha$ ) (in our static version, we hold the interest rate fixed). By assuming household preferences are of the GHH form the elasticity of aggregate demand with respect to the wage is just $1+\varepsilon$. The condition, $1+\varepsilon>\eta \rho(1-\alpha)$ simply ensures that the demand and intermediate input effects dominate the reduced marginal cost arising from the reduction in the wage.

This result is useful for understanding our results in the dynamic economy below. If we assume a labor supply elasticity of 2.6 , labor share of .66, input share of .5 and an elasticity of substitution of 10, then we would expected shocks to the collateral constraint to generate an aggregate recession where all firms decrease output (at least steady state to steady state).

\subsubsection{The Sensitivity of Output with respect to Collateral Shocks Depends on External Financing}

We argue that data on external financing is a useful source of information to discipline the importance of the role financial markets play in reallocating funds from cash-rich, low productivity firms to cash-poor, high productivity firms and that the responsiveness of economic 
output to financial market shocks depends on the importance of this role. In this section, we use a stylized version of our dynamic model to illustrate this point theoretically.

In Appendix B:, we analyze a simplified version of our dynamic model in which there are only privately held firms, goods are perfect substitutes, households do not save, and the productivity process is i.i.d across firms and time. This version of our model corresponds loosely to the theoretical models considered by Kiyotaki and Moore (2008) and, more specifically, Kocherlakota (2009). Specifically, we assume that in every period, each firm has a probability $\pi$ of having productivity equal to 1 and probability $1-\pi$ of having probability equal to 0. By assuming that shocks are i.i.d. and goods are perfect substitutes, we are able to construct closed form solutions for the equilibrium wage, output, and steady-state wealth as well as compute external financing by hand.

We then consider the impact of changes in the tightness of the collateral constraint, $\lambda$, in economies with different probability of being productive, $\pi$. One difficulty in this analysis is that for economies with different productivity probabilities, $\pi$, a given change in $\lambda$ represents a different size "shock" to the economy. To account for this effect, for each $\pi$-economy, we choose the collateral constraint parameter, $\lambda(\pi)$ so that the aggregate debt-to-assets ratio in the model is the same across all $\pi$-economies. Then, for each $\pi$-economy, we compare steady state wealth and output in the $\lambda(\pi)$ economy to that in the economy when $\lambda=1$, in other words, the autarkic version of that economy. Therefore, we are considering shocks to the collateral constraint in each $\pi$ economy that cause the aggregate debt-to-asset ratio to fall from some constant to 0 . We show that the difference in steady state wealth between the $\lambda(\pi)$, high debt economy, and the $\lambda=1$, no debt economy is monotonically decreasing in the probability of receiving a high productivity shock. At the same time, the amount of external financing in the $\lambda(\pi)$ high debt economy is monotonically decreasing in $\pi$. In this sense, data on external financing is useful for disciplining the macroeconomic impact of shocks to collateral constraints. We state this result from Appendix B: as the following proposition. ${ }^{6}$

Proposition 6. Suppose $0<r<\frac{1}{\beta}-1$. Let $\pi \in[\underline{\pi}, \bar{\pi}]$ and define $\lambda(\pi)$ such that the debt-toasset ratio in the $\pi$-economy with parameter $\lambda(\pi)$ is equal to $\bar{B}$. If for all $\pi, \frac{1}{\beta}<\lambda(\pi)<\frac{1}{\beta(1-\pi)}$ then external financing is decreasing in $\pi$ and $\log (\bar{A}(\lambda(\pi), \pi)-\log (\bar{A}(1), \pi)$ is decreasing in $\pi$. (The result is the same for output).

The intuition for this result is straightforward. Firms earn higher interest on financial wealth when they are productive. The greater is the probability of being productive, the higher is the financial wealth of firms in steady state. A fixed stock of debt relative to

\footnotetext{
${ }^{6}$ We have proved a similar result for local changes in $\lambda$ however this result requires additional sufficient conditions.
} 
total assets generates a larger amount of wealth relative to autarky for an economy with a lower probability of being productive since firms cannot accumulate as much financial wealth. As a result, the difference between the autarky and the credit economy is largest when the probability of being productive is the smallest. Of course, in economies where the probability of being productive is low, when firms do become productive, they have typically experienced a long spell of being unproductive. As a result, their assets have declined and thus their available funds are low exactly when their investment exhibits a large increase. As a result, economies with low probability of becoming productive exhibit a large degree of external financing.

\section{Calibration and Quantitative results}

In this section, we calibrate the model and undertake exercises intended to illustrate the contribution of changes in financial frictions to business cycle frequency fluctuations. We calibrate the steady state of the model and then perform impulse response analysis. We compare our results to those from a standard real business cycle model.

\subsection{Calibration}

Here we describe our calibration strategy. We have two sets of parameters: parameters that are typically used in macroeconomic models, and parameters that we use our model to pin down. As for the first set of parameters, we fix the discount rate to 0.96, targeting an annual real interest rate of $4 \%$. We set the annual depreciation rate, $\delta$, to be 0.07 and we assume that the exit rate of privately held firms, $1-\zeta$, is $10 \%$. This exit rate implies a ten year survival rate of 34\%, and is consistent with estimates from Dunne et al. (1988). Since $\zeta$ is a major determinant of financial flows for privately held firms ${ }^{7}$, later, we perform robustness checks on $\zeta$. Furthermore, we set $\alpha$, one of the parameters in the firm production function to 0.3 and choose the elasticity of substitution across firms or goods to be $\rho=4$ in line with estimates from micro data evidence (see Burstein and Hellwig (2008)).

We parameterize household preferences as

$$
U(c, l)=\log \left(c-\frac{\psi}{1+\frac{1}{\varepsilon}} l^{1+\frac{1}{\varepsilon}}\right)
$$

We choose an elasticity of labor supply, $\varepsilon$, to be 2.6. We assume that there are no wealth

\footnotetext{
${ }^{7}$ When $\zeta$ is high, firms have stronger incentives to accumulate assets in order to overcome their collateral constraint in the future. This could lower the amount of debt issued by privately held firms. This can dampen the effect of a shock to $\lambda$ on aggregate output.
} 
effects on the labor-leisure tradeoff to highlight the role of the complementarity between publicly held and privately held firms in our model, but note that choosing a more standard form will reduce the sensitivity of output to changes in the severity of financial frictions because declines in output by constrained firms will generate increases in output by unconstrained firms. Our choice of $\varepsilon$ is in the range of macro estimates as documented by Chetty et al. (2011), among others.

Next, we describe the set of parameters that are calibrated using our model. The key parameters of the steady state calibration are the tightness of the collateral constraint and the process for idiosyncratic firm level productivity. We calibrate $\lambda$, the tightness of the collateral constraint to match average aggregate debt to total assets in the U.S. economy since 1986, which is 0.49 . We assume that firm level productivity follows an $\mathrm{AR}(1)$ process so that

$$
\log z_{i t}=\rho_{z} \log z_{i t-1}+\varepsilon_{i t}, \varepsilon_{i t} \sim N\left(0, \sigma_{z}^{2}\right) .
$$

We calibrate the standard deviation of the innovations to log productivity to match the variance in the firm-level debt-to-asset ratio in our Amadeus sample, which is 0.28 . We calibrate the persistence of the productivity process, $\rho_{z}$, so that in the model, $93 \%$ of investment by privately held firms is externally financed (as in our benchmark Amadeus sample).

The measure of privately held firms, $s$, is chosen so that privately held firms account for $40 \%$ of corporate gross output. We compute this share by calculating the share of firms in Compustat from gross output. ${ }^{8}$ Figure 4.1, plots this share from 1987 to 2009.

We choose the value of $\eta$ (from the firm's production function) so that input's share of gross output is .43 (Jones (2011)). Lastly, we choose $\psi$, which scales household's disutility of labor supply to generate aggregate hours of 0.3 . The calibrated parameters are summarized in table 4.1.

Before discussing the results of our quantitative exercise, it is useful to discuss how well the model does in capturing some of the key moments in data. In particular, we are interested in statistics relevant for privately held firms. In our calibration strategy, we have calibrated the productivity process for firms to match external financing by private firm as well the variance of debt to assets. One way to check the validity of our estimates is to compare employment fluctuations in our model to data, as documented by Davis et al. (2007). In our calibrated model, the cross-sectional dispersion in employment growth is 0.3 for privately held firms while in data it is 0.4. We take this as a fairly close estimate and the amount of idiosyncratic risk faced by our firms are not very far from that presented by Davis et al.

\footnotetext{
${ }^{8}$ We have calculated gross output by calculating the gross output at industry levels. This data is available from BEA only from 1987. Moreover, this figure includes gross output by non-corporations as well. That makes the share of privately held firms a bit biased upward.
} 


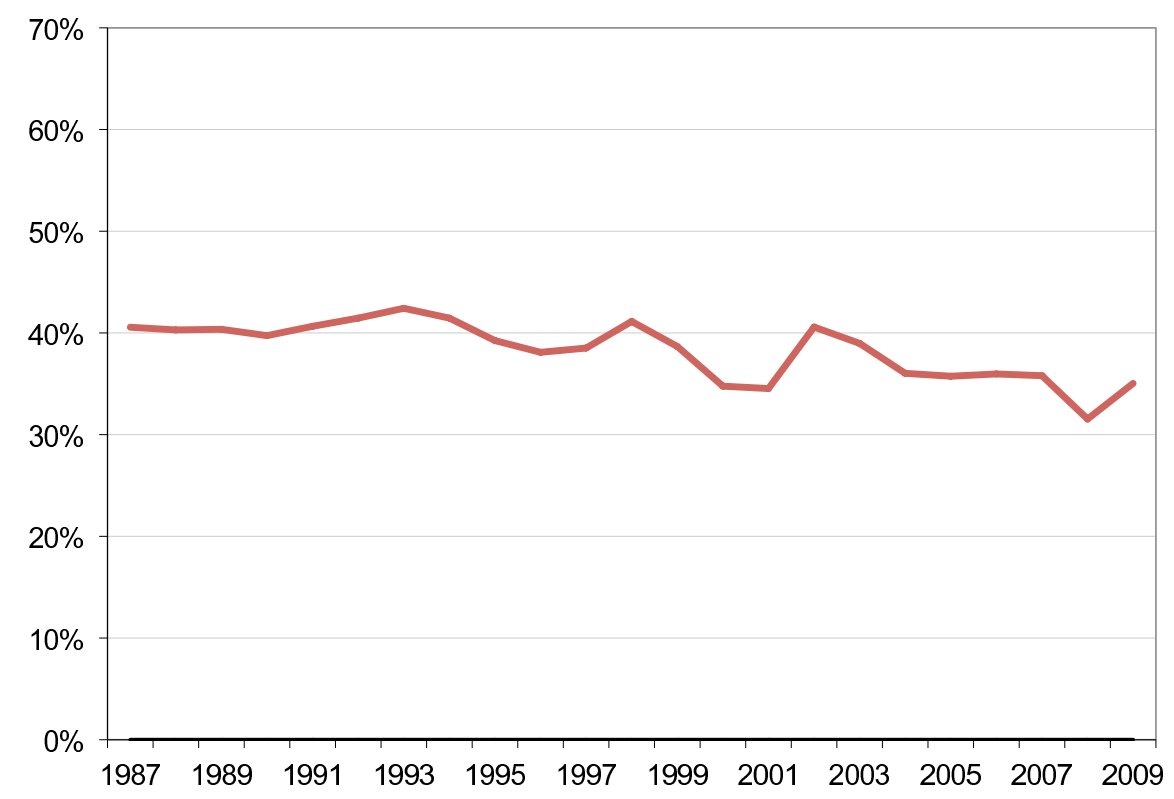

Figure 2: Share of Private Firms in Gross Output

\begin{tabular}{l|lll}
\hline \hline Parameter & Explanation & Value & Target \\
\hline$\beta$ & Discount rate & 0.96 & Annual interest rate $=0.04$ \\
$\epsilon$ & labor supply elasticity & 2.6 & Frisch elasticity \\
$\rho$ & Elasticity of substitution & 4 & Burstein and Hellwig (2008) \\
$\alpha$ & Share of capital & 0.3 & \\
$\delta$ & Depreciation rate & 0.07 & \\
$\zeta$ & Survival rate & 0.9 & Dunne et al. (1988) \\
\hline & calibrated using the model & & \\
\hline$\psi$ & Coefficient on leisure & 0.10 & Aggregate hours $=0.3$ \\
$s$ & Measure of private firms & 0.42 & Share of gross output by private \\
& Share of Intermediated Inputs & 0.43 & Input share of gross output $=0.43$ \\
$\eta$ & & & (Jones, 2011) \\
$\lambda$ & Tightness of collateral constraint & 3.50 & Average debt to asset ratio $=0.49$ \\
$\rho_{z}$ & Persistence of productivity shocks & 0.70 & Net financial inflow $=0.93$ \\
$\sigma_{z}$ & Variance of productivity shocks & 0.65 & Variance of debt to asset \\
\hline
\end{tabular}

Table 1: Calibrated Parameter Values

(2007).

\subsection{Shocks to $\lambda$}

We now analyze the response of the economy to a purely unanticipated shock to $\lambda$. We impose an initial shock to $\lambda$ which then returns back to its steady state value. On impact, 
agents in the economy immediately learn the entire path of $\lambda$. Our goal is to understand how large a response in output is generated by a "typical" financial shock when agents place zero probability on this event occurring.

We fix the decay of the impulse so that the (annual) half-life of the shock to $\lambda$ is 1 year. We choose the size of the initial impulse so that on impact, the shock generates a one standard deviation decline in aggregate debt-to-total assets in our model economy. In the U.S., since 1986, the standard deviation of the aggregate debt-to-total assets ratio for non-farm non-financial corporate businesses is 0.015 or roughly $3 \%$ (after using the HP-filter to filter out longer frequency movements). Figure (13) displays the residuals of the aggregate debt-to-assets ratio at an annual frequency.

Figure 16 displays the path of deviations from steady state values of the collateral constraint parameter, $\lambda$, the aggregate debt-to-total asset ratio, and measured productivity.

We find that the impulse to the economy generates a roughly $.45 \%$ decline in gross value added on impact (we define gross value added as Gross Output less the aggregate use of intermediate inputs). As we will discuss below, this is roughly $70 \%$ as large as the response of output in our model to a "typical" productivity shock; ie: an aggregate productivity shock that causes measured productivity to fall by one standard deviation of the measured solow residuals in the U.S. economy. In this sense, we view the effect of the financial shock as sizeable.

Given that the aggregate capital stock is fixed on impact, it is perhaps surprising that output and labor fall on impact of the shock. This fall occurs because the tighter collateral constraint leads constrained firms to reduce demand for capital and unconstrained firms to increase their demand for capital (the rental rate of capital falls). The set of unconstrained firms is typically made up of all publicly held firms and those privately held firms with low productivity (relative to their assets). Thus, this reallocation of capital to unconstrained firms implies more capital is installed by unproductive firms, leading to a decline in aggregate productivity. This can be seen in the fourth panel of figure 16, which shows that measured productivity on impact falls by $0.65 \%$.

Second, we find that output does not recover by half until 2.5 years after the impulse even though the shock has recovered by half after 1 year. In this sense, financial shocks have persistent effects on output.

Third, we find that a financial shock causes consumption, employment, and investment to move in the same direction of output. The paths for these objects, along with the paths for wages and interest rates are depicted in Figure 17. The decline in employment is driven by the reduction in the wage rate which, in turn, falls due to the decline in measured productivity. The interest rate declines because the financial shock causes aggregate demand for capital 
to fall. The decline in the wage and rental rate of capital, which is also the rate of return households earn on their savings make final good consumers poorer and lead them to reduce their consumption.

Fourth, Figure 18 displays the responses of sales by publicly and privately held firms as well as the gross output share of the publicly held firms. We find that although sales of privately held firms fall by roughly $1.5 \%$ on impact and remain below steady state for over 10 years, sales by publicly held firms actually rise by roughly .2\% on impact of the shock. By the second year after the impulse, sales of publicly held firms return to steady state, and by the third year of the shock are below trend. The output share of publicly held firms, however, remains above trend for the duration of the impulse.

The different response of sales by publicly and privately held firms initially is driven by the increased use of capital by publicly held firms, none of which face binding collateral constraints, and the fact that in response to the roughly $0.1 \%$ decline in the wage rate, aggregate labor does not decline dramatically. Within two periods, however, as the supply of capital falls, in response to the tightening of the collateral constraints, sales of both types of firms are below the initial steady state. In this sense, our model is capable of generating co-movement across the publicly held and privately held sectors, at least in the medium term.

To comparing the response of these sectors in our model to data, in Figure 14 we plot gross output of all non-financial firms in Compustat in the U.S. and gross output of all non-financial firms in the U.S. (data from the BEA) as percentage deviations from a linear trend. This figure shows that output of publicly held firms in compustat is highly correlated with that of all non-financial firms, but not perfectly so.

In terms of the share of output accounted for by publicly held firms in Compustat, which we plot (again as deviations from trend) in figure 15, we observe that this share varies by roughly $6 \%$ but not only around business cycle dates. For example, although the share of output by Compustat firms is above trend from 2000 to 2001 and rises from 2007 to 2008, there are also significant movements (both increases and decreases) in the middle of business cycle recoveries. Given these irregulat movements, we choose not use this evidence to discipline our model.

The fact that output of publicly held firms falls below trend results only from the complementarity in production across firms that we have discussed theoretically above. We have performed sensitivity analysis with respect to the elasticity of substitution across goods, $\rho$, the labor supply elasticitiy $\epsilon$ and the input-output structure governed by the parameter $\eta$.

However, in each of these cases, when we have re-calibrated our model to be consistent with our target moments, we find that our benchmark result, that the response of aggregate 
output to our calibrated financial shock is roughly $0.45 \%$ does not vary. What does change is the composition of the response of privately versus publicly held firms. For example, with a lower labor supply elasticitiy, a higher elasticity of substitution across goods, or no inputoutput structure, we find that the gross output of publicly held firms does not fall below trend at any point along the impulse response path. In this sense, we view trade linkages as an important mechanism for generating co-movement of firms in response to a financial shock.

Figure 19 displays the effect of the financial shock on the use of external funds measured in the model as in our statistic in equation (2). Use of external funds declines on impact and recovers back to its steady level. This result is driven primarily by the fact that most firms that use external funds are constrained firms, and investment of constrained firms falls faster than aggregate investment since most unconstrained firms actually increase investment in response to lower wages and capital rental rates.

\subsection{Shocks to Aggregate Productivity}

We now compare the effects of financial shocks to the effects of aggregate productivity shocks in our model. We perform a similar exercise as when we analyze financial shocks, only in this section we consider the transition dynamics the result from a purely unanticipated decline in aggregate productivity which slowly returns to steady state. Again, we fix the half-life of the impulse to 1 year. In order to compare the magnitudes of the effects, we choose the size of the shock so that measured productivity in the model falls on impact by one standard deviation of the measured solow residual in the United States. This corresponds to roughly a $1 . \%$ decline in measured productivity (at an annual rate).

We also compare the effects of productivity shocks in a version of our model without collateral constraints. Specifically, we analyze our model economy in the case where there are no privately held firms, but the process for idiosyncratic risk for publicly held firms is the same as in our calibrated model above.

Figure 20 displays the impulse path for measured productivity following the shock to aggregate productivity and gross value added (and, as in all of these pictures, the dashed line represents the corresponding path from the response of our model economy to the calibrated financial shock). First, observe that a financial shock generates a decline in measured productivity roughly $70 \%$ as large as this shock to measured productivity and that measured productivity recovers faster in response to an aggregate productivity shock than to a financial shock.

Regarding gross value added, we find that a typical financial shock are roughly $70 \%$ as 
large as the effects of a typical productivity shock. Note that in this model, the effects of productivity shocks are dampened. In other words, a $1 \%$ decline in measured productivity causes gross value added to fall by only roughly $0.7 \%$. This is due primarily to the monopoly distortions, which become less severe in response to a decline in aggregate productivity. Also note that the model with and without collateral constraints generate roughly the same effect on output. This is a well known result going back at least to Kocherlakota (2000).

Finally, figure ?? depicts the response of aggregate debt-to-total assets ratio as well as the use of external funds in the model (with collateral constraints). Notice that debt-toassets do not move at all and the use of external funds as defined in equation (2) rises in response to the shock. Demand for debt by firms falls as the level of capital they optimally want to install is lower in response to the aggregate productivity shock, but their demand for capital has also fallen by roughly an equivalent amount, causing the debt-to-asset ratio to remain roughly stable. The response of the use of external funds, on the other hand, is in the opposite direction of the response following a financial shock. The reason for this is that when aggregate productivity declines, the collateral constraints for constrained firms are relaxed as the unconstrained level of investment they want to undertake is lower. As a result, investment by constrained firms falls by less than the aggregate, leading the use of external funds to rise.

In this sense, although productivity shocks and financial shocks have similar size effects on output, they affect financial flows in very different ways. It is not surprising that time series variation in aggregated financial flows statistics may be useful in distinguishing between productivity and financial shocks. Given longer time series data on financial flows for privately held firms, these differences could be useful in undertaking just such an analysis.

\subsection{Sensititivy with Respect to Exit Risk}

We conclude our quantitative section with a brief discussion of the sensitivity of our results to the magnitude of the exit risk in our model, which is governed by the parameter $\zeta$. First, consider an increase in the survivial rate, holding the remaining parameters of the model fixed. IN this example, we increase $\zeta$ from 0.9 to 0.95 .

The steady state of this economy differs significantly along the key financial flows moments that we target from that of our benchmark economy. In particular, in this economy, the aggregate debt-to-assets ratio is $0.30 \%$ (instead of 0.49 ) and the use of external funds is 1.63 (instead of .93). The main difference between these economies is that the average wealth of owners of privately held firms is higher. In fact, the book value of the net worth of owners of privately held firms is $60 \%$ of aggregate capital; in our benchmark, this value is 
$20 \%$ of aggregate capital.

Somewhat surprisingly, the use of external funds in this model is significantly higher than in our benchmark economy. The difference is that in this version of the model, most use of external funds comes in the form of changes in negative debt holdings; in other words, firms in this economy use external funds when they draw down against their net worth. One way to see this difference is to note that in this economy, rougly $20 \%$ of privately held firms face binding collateral constraints in any period (as opposed to $40 \%$ in our benchmark), but $26 \%$ of firms use external funds for investment (as opposed to 17\%). In addition, over $35 \%$ of owners of privately held firms have a negative debt position. These results combine to ensure that the aggregate debt-to-assets ratio is too low relative to our benchmark economy.

The consequence of this difference is that if we impose the same impulse response as in our benchmark model, aggregate output falls by only $0.2 \%$. We view this kind of sensitivity of our result that financial shocks have sizeable effects as arising for the wrong reasons. That is, the effects are small only because these firms do not use as much debt as they do in the data.

\section{Conclusion}

We have analyzed the effect of disturbances to financial markets in a quantitative model where financial frictions operate through collateral constraints. We used data on firm-level financial flows to discipline the importance of financial markets in the model and found that the decline in macroeconomic output generated by a calibrated tightening in the collateral constraint is roughly consistent with that generated by a calibrated decline in aggregate productivity in a standard real business cycle model.

These results suggest that shocks to collateral constraints may contribute to a significant fraction of business cycle volatility. A quantitative version of our model with aggregate shocks to collateral constraints and productivity is in progress.

An important question for future analysis is the extent to which our quantitative results are sensitive to our decision to model collateral constraints as working capital constraints as opposed to constraints on new investment. We also intend to study this question by analyzing a similar version of our model where capital is not fully mobile and the financial frictions manifest as constraints on new investment. 


\section{Appendix A: Static Version of our Model}

In this Appendix, we develop a static version of our model in order to establish the main economic mechanism of the model. We use the static model to illustrate how shocks to the collateral constraint affects both firms for whom the constraint binds and also those for whom the constraint does not bind. We derive a sufficient condition on the model parameters under which a tightening of the collateral constraint leads all firms to reduce output in equilibrium.

Consider a static economy populated by a continuum of intermediate good firms, a representative final good producer, and a representative household.

Intermediate Good Producers. Each intermediate good firm $i \in[0,1]$ has an asset level $a_{i}$ and productivity $z_{i}$. Moreover, $\left(a_{i}, z_{i}\right)$ is distributed according to $F(a, z)$. An intermediate good firm with productivity $z_{i}$ and assets $a_{i}$, rents labor, $l$, and capital, $k$, rents out its assets $a_{i}$ and purchases an amount of the final good, $I$, to be used as an input to production according to the production function

$$
q_{i}=z_{i}^{\frac{1}{\rho-1}}\left(k^{\alpha} l^{1-\alpha}\right)^{\eta} I^{1-\eta}
$$

Each firm may rent capital up to a multiple of the value of the firm's assets. Specifically, we impose a collateral constraint so that the amount of capital rented by a firm with asset level $a_{i}$ is bounded by $\lambda a_{i}$ where $\lambda \geq 1$. One can rationalize this type of constraint by a model of moral hazard or limited enforcement. In line with the rest of the literature, we impose this constraint and do not provide a formal micro foundation for it.

Final Good Producer. The final good producer uses a bundle of inputs purchased from intermediate good firms and takes their prices as given. Given a bundle $\left\{q_{i}\right\}_{i \in[0,1]}$, the final good producer uses the following Dixit-Stiglitz production function:

$$
Q=\left[\int_{0}^{1} q_{i}^{\frac{\rho-1}{\rho}} d F(i)\right]^{\frac{\rho}{\rho-1}}
$$

with $\rho>1$.

Households. We assume that there is a representative households who buys the final good and provides labor to intermediate good producers. Following Greenwood et al. (1988), we assume that household preferences are given by

$$
U\left(c-\psi \frac{l^{1+\frac{1}{\varepsilon}}}{1+\frac{1}{\varepsilon}}\right)
$$

Markets. We assume that the labor market is competitive at wage level $w$. As for capital 
market, we assume that the economy is small and open. That is, there exist suppliers of capital that have deep pockets and inelastically supply capital at a given interest rate $r$. This is an assumption that simplifies the analysis; under this assumption, when we perform comparative statics, we do not need to consider general equilibrium effects that arise from changes in the interest rate for capital. Similar analysis can be done in a closed economy.

Moreover, we assume that there is monopolistic competition across intermediate good firms and prices are given by $p_{i}$. The final good producer takes these prices as given and intermediate good producers take the demand function for intermediate output as given. We normalize the price of final good to 1.

Given the above market structure, the final good producer's maximization problem is given by

$$
\max _{q_{i}}\left[\int_{0}^{1} q_{i}^{\frac{\rho-1}{\rho}} d F(i)\right]^{\frac{\rho}{\rho-1}}-\int_{0}^{1} p_{i} q_{i} d F(i) .
$$

The resulting demand for intermediate good $i$ is given by

$$
q_{i}^{-\frac{1}{\rho}} Q^{\frac{1}{\rho}}=p_{i}
$$

Given this demand function, each intermediate good firm maximizes its profit subject to its collateral constraint:

$$
\pi_{i}=\max _{k, l, I, p_{i}} p_{i} z_{i}^{\frac{1}{\rho-1}}\left(k^{\alpha} l^{1-\alpha}\right)^{\eta} I^{1-\eta}-w l-r k-I+r a_{i}
$$

subject to

$$
\begin{aligned}
p_{i} & =Q^{\frac{1}{\rho}}\left(z_{i}^{\frac{1}{\rho-1}}\left(k^{\alpha} l^{1-\alpha}\right)^{\eta} I^{1-\eta}\right)^{-\frac{1}{\rho}} \\
k & \leq \lambda a_{i}
\end{aligned}
$$

We say that a firm is financially constrained if the collateral constraint is binding for a firm in equilibrium and is financially unconstrained otherwise.

To complete the definition of competitive equilibrium, we need to specify the household's optimization problem as well as market clearing conditions. The representative household's optimization problem is given by

$$
\max _{c, L} U\left(c-\psi \frac{L^{1+\frac{1}{\varepsilon}}}{1+\frac{1}{\varepsilon}}\right)
$$


subject to

$$
c \leq w L+\int_{0}^{1} \pi_{i} d F(i) .
$$

Labor market and product market clearing are given by

$$
\begin{aligned}
\int_{0}^{1} l_{i} d F(i) & =L \\
c+\int_{i} I_{i} d F(i) & =Q .
\end{aligned}
$$

Hence a competitive equilibrium of this economy is given by $\left\{\left\{k_{i}, l_{i}, I_{i}, p_{i}\right\}_{i \in[0,1]}, c, L, Q, w\right\}$ that satisfies the above conditions.

Because of monopolistic competition, the revenue function of the firm exhibits decreasing returns to scale. As a result, for every $z$, there is an unconstrained optimal scale, which is increasing in $z$. Not surprisingly, then, every $z$, there is a threshold in assets, say $a^{*}(z)$ such that firms with assets and productivity $(a, z)$ with $a \geq a^{*}(z)$ are financially unconstrained and if $a<a^{*}(z)$ the firm is financially constrained. We state this result along with optimal capital, labor, and intermediate input decisions for firms in the following lemma (the proof is omitted).

Lemma 7. For every $z$, there exists $a^{*}(z)$ such that for $a \geq a^{*}(z), k(a, z) \leq \lambda a$ and for $a<a^{*}(z), k=\lambda a$. Furthermore, $a^{*}(z)$ satisfies

$$
a^{*}(z)=\frac{1}{\lambda}[\nu(1-\eta)]^{\frac{(1-\eta) \nu}{1-\nu}}\left(\frac{\alpha \eta \nu}{\hat{r}}\right)^{1+\frac{\alpha \eta \nu}{1-\nu}}\left(\frac{\nu(1-\alpha) \eta}{w}\right)^{\frac{(1-\alpha) \eta \nu}{1-\nu}} Q z
$$

If $a \geq a^{*}(z)$ then

$$
k(a, z)=[\nu(1-\eta)]^{\frac{(1-\eta) \nu}{1-\nu}}\left(\frac{\alpha \eta \nu}{\hat{r}}\right)^{1+\frac{\alpha \eta \nu}{1-\nu}}\left(\frac{\nu(1-\alpha) \eta}{w}\right)^{\frac{(1-\alpha) \eta \nu}{1-\nu}} Q z
$$

if $a<a^{*}(z)$ then $k(a, z)=\lambda a$. Finally,

$$
\begin{aligned}
l & =\left(\frac{\nu(1-\alpha) \eta}{w}\right)^{\frac{1-(1-\eta) \nu}{1-(1-\alpha \eta) \nu}}(\nu(1-\eta))^{\frac{(1-\eta) \nu}{1-(1-\alpha \eta) \nu}}(Q z)^{\frac{(1-\nu)}{1-(1-\alpha \eta) \nu}} k^{\frac{\alpha \eta \nu}{1-(1-\alpha \eta) \nu}} \\
I & =\left[\nu(1-\eta)(Q z)^{1-\nu}\left(k^{\alpha} l^{1-\alpha}\right)^{\eta \nu}\right]^{\frac{1}{1-(1-\eta) \nu}}
\end{aligned}
$$

where $\nu=1-\frac{1}{\rho}$.

Given the decisions of firms along with optimal labor supply of households, we can 
characterize equilibrium output, $Q$ and the wage rate, $w$ using the production function of the final good producer and the labor market clearing conditions. Given these equilibrium values, we can show that the equilibrium wage rate is decreasing in the collateral constraint parameter $\lambda$. This final result follows because a relaxing of the constraint must increase aggregate capital demand and therefore labor demand causing the wage to rise. We have the following lemma.

Lemma 8. Any competitive equilibrium must satisfy the following:

1. $Q=\frac{1}{(1-\alpha) \eta\left(1-\frac{1}{\rho}\right)} \psi^{-\varepsilon} w^{1+\varepsilon}$,

2. The equilibrium wage, $w$, is decreasing in $\lambda$.

Proof. Given capital, labor and intermediate input demand, we can construct aggregate excess output and labor as functions of prices $r, w$, and output $Q$. Specifically, let $A^{*}=$ $\left\{(a, z): a \geq a^{*}(z)\right\}$

$$
\begin{aligned}
Q^{\nu}= & \int q^{\nu} G(d a, d z) \\
= & \left(\frac{\nu(1-\alpha) \eta}{w}\right)^{\frac{\nu \eta(1-\alpha)}{1-\nu}}(\nu(1-\eta))^{\frac{\nu(1-\eta)}{1-\nu}}\left(\frac{\alpha \eta \nu}{\hat{r}}\right)^{\frac{\alpha \eta \nu}{1-\nu}} Q^{\nu} \int_{(a, z) \in A^{*}} z G(d a, d z) \\
& +\left(\frac{\nu(1-\alpha) \eta}{w}\right)^{\frac{\nu \eta(1-\alpha)}{1-(1-\alpha \eta) \nu}}(\nu(1-\eta))^{\frac{\nu(1-\eta)}{1-(1-\alpha \eta) \nu}} Q^{\frac{\nu(1-\nu)(1-\alpha \eta)}{1-(1-\alpha \eta) \nu}} \lambda^{\frac{\alpha \eta \nu}{1-(1-\alpha \eta) \nu}} \int_{(a, z) \notin A^{*}} z^{\frac{(1-\nu)}{1-(1-\alpha \eta) \nu}} a^{\frac{\alpha \eta \nu}{1-(1-\alpha \eta) \nu}} G(d a,
\end{aligned}
$$

Labor Demand is just a function of output. We have

$$
l=\left(\frac{(1-\alpha) \eta \nu}{w}\right) Q^{1-\nu} q^{\nu}
$$

Thus

$$
\int l G(d a, d z)=\left(\frac{(1-\alpha) \eta \nu}{w}\right) Q^{1-\nu} \int q^{\nu} G(d a, d z)
$$

Household labor supply given our assumed form for household preferences (GHH) is just $\psi^{-\varepsilon} w^{\varepsilon}$. Thus labor market clearing is simply

$$
\psi^{-\varepsilon} w^{\varepsilon}=\left(\frac{(1-\alpha) \eta \nu}{w}\right) Q
$$

and, therefore, aggregate output in equilibrium satisfies

$$
Q=\psi^{-\varepsilon}((1-\alpha) \eta \nu)^{-1} w^{1+\varepsilon}
$$


Re-write $Q$ from (17) as

$$
\begin{aligned}
1= & \left(\frac{\nu(1-\alpha) \eta}{w}\right)^{\frac{\nu \eta(1-\alpha)}{1-\nu}}(\nu(1-\eta))^{\frac{\nu(1-\eta)}{1-\nu}}\left(\frac{\alpha \eta \nu}{\hat{r}}\right)^{\frac{\alpha \eta \nu}{1-\nu}} \int_{(a, z) \in A^{*}} z G(d a, d z) \\
& +\left(\frac{\nu(1-\alpha) \eta}{w}\right)^{\frac{\nu \eta(1-\alpha)}{1-(1-\alpha \eta) \nu}}(\nu(1-\eta))^{\frac{\nu(1-\eta)}{1-(1-\alpha \eta) \nu}} Q^{\frac{-\alpha \eta \nu}{1-(1-\alpha \eta) \nu}} \lambda^{\frac{\alpha \eta \nu}{1-(1-\alpha \eta) \nu}} \int_{(a, z) \notin A^{*}} z^{\frac{(1-\nu)}{1-(1-\alpha \eta) \nu}} a^{\frac{\alpha \eta \nu}{1-(1-\alpha \eta) \nu}} G(d a, d z)
\end{aligned}
$$

Analyzing the derivative with respect to $\lambda$, we have

$$
\begin{aligned}
0= & \left(\frac{\nu(1-\alpha) \eta}{w}\right)^{\frac{\nu \eta(1-\alpha)}{1-\nu}}(\nu(1-\eta))^{\frac{\nu(1-\eta)}{1-\nu}}\left(\frac{\alpha \eta \nu}{\hat{r}}\right)^{\frac{\alpha \eta \nu}{1-\nu}} \int_{(a, z) \in A^{*}} z G(d a, d z) \\
& \times\left[-\frac{\nu \eta(1-\alpha)}{1-\nu} \frac{1}{w} \frac{d w}{d \lambda}\right] \\
& +\left(\frac{\nu(1-\alpha) \eta}{w}\right)^{\frac{\nu \eta(1-\alpha)}{1-(1-\alpha \eta) \nu}}(\nu(1-\eta))^{\frac{\nu(1-\eta)}{1-(1-\alpha \eta) \nu}} Q^{\frac{-\alpha \eta \nu}{1-(1-\alpha \eta) \nu}} \lambda^{\frac{\alpha \eta \nu}{1-(1-\alpha \eta) \nu}} \int_{(a, z) \notin A^{*}} z^{\frac{(1-\nu)}{1-(1-\alpha \eta) \nu}} a^{\frac{\alpha \eta \nu}{1-(1-\alpha \eta) \nu}} G(d a, d z) \\
& \times\left[-\frac{\nu \eta(1-\alpha)}{1-(1-\alpha \eta) \nu} \frac{1}{w} \frac{d w}{d \lambda}-\frac{\alpha \eta \nu}{1-(1-\alpha \eta) \nu} \frac{1}{Q} \frac{d Q}{d \lambda}+\frac{\alpha \eta \nu}{1-(1-\alpha \eta) \nu} \frac{1}{\lambda}\right]
\end{aligned}
$$

Suppose $\frac{d w}{d \lambda} \leq 0$. Then $\frac{d Q}{d \lambda} \leq 0$. Then we must have

$$
-\frac{\nu \eta(1-\alpha)}{1-(1-\alpha \eta) \nu} \frac{1}{w} \frac{d w}{d \lambda}-\frac{\alpha \eta \nu}{1-(1-\alpha \eta) \nu} \frac{1}{Q} \frac{d Q}{d \lambda}+\frac{\alpha \eta \nu}{1-(1-\alpha \eta) \nu} \frac{1}{\lambda} \leq 0
$$

and since

$$
\frac{\alpha \eta \nu}{1-(1-\alpha \eta) \nu} \frac{1}{\lambda}>0
$$

we have

$$
\frac{\nu \eta(1-\alpha)}{1-(1-\alpha \eta) \nu} \frac{1}{w} \frac{d w}{d \lambda}+\frac{\alpha \eta \nu}{1-(1-\alpha \eta) \nu} \frac{1}{Q} \frac{d Q}{d \lambda}>0
$$

but the coefficients are all positive so this is a contradiction. As a result, the wage must be increasing in $\lambda$.

We are now ready to state our necessary and sufficient condition for a tightening of the collateral constraint to cause both financially constrained and financially unconstrained firms to decrease output. Using the optimal production decisions of firms, we can show that a 
financially unconstrained firm's output satisfies

$$
\begin{aligned}
q_{i} & =\left(\frac{\nu(1-\alpha) \eta}{w}\right)^{\frac{\eta(1-\alpha)}{1-\nu}}(\nu(1-\eta))^{\frac{1-\eta}{1-\nu}}\left(\frac{\alpha \eta \nu}{\hat{r}}\right)^{\frac{\alpha \eta}{1-\nu}} Q z^{\frac{1}{\nu}} \\
& =\kappa w^{-\frac{\eta(1-\alpha)}{1-\nu}} Q
\end{aligned}
$$

A one percent increase in $w$ causes $Q$ to increase by $1+\varepsilon$ percent and $w^{-\frac{\eta(1-\alpha)}{1-\nu}}$ to decrease by $\frac{\eta(1-\alpha)}{1-\nu}$. Hence, output of financially unconstrained firms is increasing in $w$ or $\lambda$ if and only if $1+\varepsilon \geq \eta \rho(1-\alpha)$. We then have the following proposition.

Proposition 9. Suppose there exists a positive measure set of constrained firms. If $1+\varepsilon \geq$ $\eta \rho(1-\alpha)$, then output of all firms is increasing in the collateral constraint parameter, $\lambda$. 


\section{Appendix B: External Financing in a Simplified Ver- sion of our Dynamic Model}

In this section, we analyze a version of our model with perfect competition, perfect substitutes, and an i.i.d. process for firm level productivity. Specifically, we assume that in every period, each firm has a probability $\pi$ of having productivity equal to 1 and probability $1-\pi$ of having probability equal to 0 . We solve analytically for the equilibrium and the amount of external financing used by firms in the model. We then compare the effect of changes in the collateral constraint parameter, $\lambda$, across economies with different probabilities of high productivity, $\pi$.

In particular, for each $\pi$-economy, we choose the collateral constraint parameter, $\lambda(\pi)$ so that the aggregate debt-to-assets ratio in the model is the same across all $\pi$-economies. We show that even though the debt-to-asset ratio is held constant, the amount of external financing is decreasing the probability of receiving a high productivity shock. Then, for each $\pi$-economy, we compare steady state wealth in the $\lambda(\pi)$ economy to that in the economy when $\lambda=1$, in other words, the autarkic version of that economy. We show that the difference in steady state wealth between the $\lambda(\pi)$, high debt economy, and the $\lambda=1$, no debt economy monotonically decreasing in the probability of receiving a high productivity shock.

\section{Model and Solution}

In this simplified version of our model, firms are identical, produce a homogeneous final output good, and the process for firm level productivity is given by

$$
z_{t}=\left\{\begin{array}{c}
1 \mathrm{w} \cdot \text { prob } \pi \\
0 \mathrm{w} \cdot \text { prob } 1-\pi
\end{array}\right.
$$

where the shocks are independent and identically drawn across firms and time. We assume a small open economy with a fixed interest rate that satisfies $0 \leq r \leq \frac{1}{\beta}-1$.

The problem of a firm in any period can be written recursively as

$$
V(a, z)=\max \ln (c)+\beta E V\left(a^{\prime}, z^{\prime}\right)
$$

subject to

$$
c+a^{\prime} \leq(1+r) a+\max _{k \leq \lambda a, l} z k^{\alpha} l^{1-\alpha}-w l-(r+\delta) k
$$


Clearly a firm with $z=0$ chooses $k=0, l=0$. It is straightforward to show that profits for a firm with $z=1$ are given by

$$
\left[\alpha\left(\frac{1-\alpha}{w}\right)^{\frac{1-\alpha}{\alpha}}-(r+\delta)\right] \lambda a
$$

Using this result, we may write the recursive problem of the firm as

$$
V(a, z)=\max \ln (c)+\beta E V\left(a^{\prime}, z^{\prime}\right)
$$

s.t.

$$
c+a^{\prime} \leq\left\{z \lambda\left[\alpha\left(\frac{1-\alpha}{w}\right)^{\frac{1-\alpha}{\alpha}}-(r+\delta)\right]+(1+r)\right\} a .
$$

Given our assumed form of preferences along with i.i.d. shock process for productivity, we immediately have that the savings functions are linear in asset holdings and given by

$$
\begin{aligned}
& a^{\prime}(a, 1)=\beta\left\{\lambda\left[\alpha\left(\frac{1-\alpha}{w}\right)^{\frac{1-\alpha}{\alpha}}-(r+\delta)\right]+(1+r)\right\} a \\
& a^{\prime}(a, 0)=\beta(1+r) a .
\end{aligned}
$$

The law of motion for assets in a steady state equilibrium yields the equilibrium wage rate which must satisfy

$$
1=\beta(1+r)+\beta \pi \lambda\left[\alpha\left(\frac{1-\alpha}{w}\right)^{\frac{1-\alpha}{\alpha}}-(r+\delta)\right] .
$$

Labor market clearing (with aggregate labor normalized to 1), then, defines steady state wealth:

$$
\bar{A}(\lambda, \pi)=\left[\frac{\alpha \beta(\pi \lambda)^{\alpha}}{1-\beta(1+r)+\beta(r+\delta) \pi \lambda}\right]^{\frac{1}{1-\alpha}} .
$$

We now turn to analyzing the amount of external financing firms rely on as well as the amount of aggregate debt and assets.

\section{External Financing}

First, as in our quantitative model, we define available funds and investment by re-writing the budget

$$
c_{t}+a_{t+1}=z_{t} k_{t}^{\alpha} l_{t}^{1-\alpha}-w l_{t}-(r+\delta) k_{t}+(1+r) a_{t}
$$


of a firm with an explicit definition of debt $b_{t}=k_{t}-a_{t}$. We then have

$$
c_{t}+k_{t+1}-(1-\delta) k_{t}=z_{t}^{\alpha} k_{t}^{\alpha} l_{t}^{1-\alpha}-w l_{t}-r b_{t}+b_{t+1}-b_{t} .
$$

We then define available funds, debt, and investment as

$$
\begin{aligned}
A F_{t} & =k_{t}^{\alpha} l_{t}^{1-\alpha}-w l_{t}-r b_{t} \\
b_{t} & =k_{t}-a_{t} \\
X_{t} & =k_{t+1}-(1-\delta) k_{t}
\end{aligned}
$$

Available funds for specific firms depends on their asset holdings and their productivity in any period. All of the derivations are included below. Available funds for firms with assets $a_{t}$ and productivity $z_{t}$ satisfy

$$
A F_{t}\left(a_{t}, z_{t}\right)= \begin{cases}a_{t}\left[\frac{1-\beta(1+r)}{\beta \pi}+\lambda \delta+r\right] & \text { if } z_{t}=\bar{z} \\ a_{t} r & \text { if } z_{t}=0\end{cases}
$$

Investment, of course, depends on productivity and assets in period $t+1$ since these factors determine the amount of capital a firm uses in period $t+1$. Since assets in period $t+1$ are functions of assets and productivity in period $t$ we may define investment as functions only of $a_{t}, z_{t}$ and $z_{t+1}$. We have

$$
X_{t}\left(a_{t}, z_{t}, z_{t+1}\right)=\left\{\begin{array}{ll}
a_{t} \lambda\left[\delta+\frac{1-\pi}{\pi}(1-\beta(1+r))\right] & \text { if } z_{t}=\bar{z}, z_{t+1}=\bar{z} \\
-a_{t}(1-\delta) \lambda & \text { if } z_{t}=\bar{z}, z_{t+1}=0 \\
a_{t} \lambda \beta(1+r) & \text { if } z_{t}=0, z_{t+1}=\bar{z} \\
0 & \text { if } z_{t}=0, z_{t+1}=0
\end{array} .\right.
$$

To aid us in defining external financing, it is useful to define the amount of excess available funds a firm has for investment. Define $A F-X$ for each firm:

$$
A F-X= \begin{cases}a_{t}\left[r+(1-\beta(1+r))\left[\frac{1-\beta \lambda(1-\pi)}{\beta \pi}\right]\right] & \text { if } z_{t}=\bar{z}, z_{t+1}=\bar{z} \\ a_{t}\left[\frac{1-\beta(1+r)}{\beta \pi}+\lambda+r\right] & \text { if } z_{t}=\bar{z}, z_{t+1}=0 \\ a_{t}[r(1-\lambda \beta)-\lambda \beta] & \text { if } z_{t}=0, z_{t+1}=\bar{z} \\ a_{t} r & \text { if } z_{t}=0, z_{t+1}=0\end{cases}
$$

We use this expression to get a sense of which firms are likely to rely on external financing. Clearly unproductive firms in period $t+1$ will not typically rely on outside funds since both firms have 0 or negative investment. Typically, the firm that switches from unproductive in 
period $t$ to productive in period $t+1\left(z_{t}=0, z_{t+1}=\bar{z}\right)$ will rely on outside funds since that firm has low available funds in period $t$ but a high amount of investment (when $\lambda$ is sufficiently large). Finally the firm that is productive in two consecutive periods $\left(z_{t}=\bar{z}, z_{t+1}=\bar{z}\right)$ will typically not rely on external funds since that firm's available funds are large in period $t$, however this is sensitive to the choice of $\lambda$ since, as $\lambda$ becomes large, even though the firm has high available funds, the amount the firm invests grows as well.

Before turning to the effects of changes in $\lambda$, we point out that in the aggregate, independent of the collateral constraint and the probability of being productive, in the aggregate firms can self finance all of their investment. To see this, notice that in the aggregate, investment is simply

$$
\delta \pi \lambda \bar{A}
$$

as productive firms are maintaining the capital stock, and available funds are given by

$$
\bar{A}\left[r+\frac{1-\beta(1+r)}{\beta}+\pi \lambda \delta\right]
$$

Thus, in the aggregate, firms can self-finance all of their investment as the aggregate excess is given by

$$
\bar{A}\left[r+\frac{1-\beta(1+r)}{\beta}\right]
$$

Finally, we have the aggregate debt-to-asset ratio:

$$
\frac{\pi(\lambda-1)}{\pi \lambda+1-\pi} .
$$

To see this final result, note that debt is just $k-a$ for firms with $k \geq a$. The only firms with $k \geq a$ are those with $z=1$. Hence, aggregate debt is simply $\pi \bar{A}(\lambda-1)$. Total assets, however, is not simply wealth, or $\bar{A}$. Total assets are capital installed by firms with $z=1$ and assets of firms with $z=0$ since these firms, in effect, have claims to financial assets. Hence, total assets are given by $\pi \lambda \bar{A}+(1-\pi) \bar{A}$. Note that the aggregate debt-to-asset ratio for any $\pi$ varies from 0 to 1 as $\lambda$ varies from 1 to $\infty$.

\section{Relating External Financing to the Importance of Financial Markets}

Consider the following exercise. For any $\pi$, choose $\lambda$ so that the debt-to-asset ratio is constant (same amount of aggregate debt relative to assets in every $\pi$ economy). Then, consider the difference in steady state wealth when $\lambda=\lambda(\pi)$ and when $\lambda=1$ (or when debtto-assets falls from the constant level to 0 ). I do this because the metric is easier to analyze 
(with respect to $\pi$ ) than is the derivative of steady state wealth. We have the following proposition.

Proposition 10. Suppose $0<r<\frac{1}{\beta}-1$. Let $\pi \in[\underline{\pi}, \bar{\pi}]$ and define $\lambda(\pi)$ such that the debt-toasset ratio in the $\pi$-economy with parameter $\lambda(\pi)$ is equal to $\bar{B}$. If for all $\pi, \frac{1}{\beta}<\lambda(\pi)<\frac{1}{\beta(1-\pi)}$ then external financing is decreasing in $\pi$ and $\log (\bar{A}(\lambda(\pi), \pi)-\log (\bar{A}(1), \pi)$ is decreasing in $\pi$. (The result is the same for output).

Proof. The assumptions of the proposition ensure that the only firm relying on external funds for investment is the firm switching from unproductive to productive. Formally, these assumptions place bounds on $\pi$ for a given $\bar{B}$. To see this, using the definition of debt-toassets in equation (20), we have that

$$
\lambda(\pi)=\frac{\bar{B}}{\pi(1-\bar{B})}+1 .
$$

Since $\lambda(\pi)$ is decreasing in $\pi$, we can replace the assumption on $\lambda(\pi)$ by ensuring that

$$
\frac{1}{\beta} \leq \frac{\bar{B}}{\bar{\pi}(1-\bar{B})}+1
$$

and

$$
\frac{\bar{B}}{\underline{\pi}(1-\bar{B})}+1 \leq \frac{1}{\beta(1-\underline{\pi})}
$$

It can be shown that these conditions are consistent with $\bar{\pi}>\underline{\pi}$.

Recall the definitions of external financing for the $\left(z_{t}=0, z_{t+1}=\bar{z}\right)$ and the $\left(z_{t}=\right.$ $\left.\bar{z}, z_{t+1}=\bar{z}\right)$ firms:

$$
\begin{aligned}
& a_{t}[r(1-\lambda \beta)-\lambda \beta] \quad \text { if } z_{t}=0, z_{t+1}=\bar{z} \\
& a_{t}\left[r+(1-\beta(1+r))\left[\frac{1-\beta \lambda(1-\pi)}{\beta \pi}\right]\right] \quad \text { if } z_{t}=\bar{z}, z_{t+1}=\bar{z}
\end{aligned}
$$

Since $0 \geq 1-\lambda \beta$, it must be that firm switching from unproductive to productive $\left(z_{t}=0, z_{t+1}=\bar{z}\right)$ uses external funds for investment and since $1-\beta \lambda(\pi)(1-\pi) \geq 0$ the firm that is productive for two consecutive periods does not use external funds for investment. Therefore, our statistic on the amount of external funds used for investment satisfies

$$
\begin{aligned}
& \frac{\pi(1-\pi)[\beta(1+r) \lambda-r]}{\pi \delta \lambda} \\
= & \frac{(1-\pi)}{\delta}\left[\beta(1+r)-\frac{r}{\lambda}\right]
\end{aligned}
$$


Using the definition of $\lambda$ in (21), we have

$$
\frac{1}{\lambda}=\frac{\pi(1-\bar{B})}{\bar{B}+\pi(1-\bar{B})}
$$

so that our external financing statistic satisfies

$$
\begin{aligned}
& \frac{(1-\pi)}{\delta}\left[\beta(1+r)-\frac{r \pi(1-\bar{B})}{\bar{B}+\pi(1-\bar{B})}\right] \\
= & \frac{(1-\pi)}{\delta}\left[\beta(1+r)-\frac{r}{\frac{\bar{B}}{\pi(1-\bar{B})}+1}\right]
\end{aligned}
$$

As a result, we immediately see that our statistic is decreasing in $\pi$. Consider now the definition of steady state wealth. We have

$$
\bar{A}(\lambda, \pi)=\left[\frac{\alpha \beta(\pi \lambda)^{\alpha}}{1-\beta(1+r)+\beta(r+\delta) \pi \lambda}\right]^{\frac{1}{1-\alpha}}
$$

and

$$
\bar{A}(1, \pi)=\left[\frac{\alpha \beta \pi^{\alpha}}{1-\beta(1+r)+\beta(r+\delta) \pi}\right]^{\frac{1}{1-\alpha}}
$$

Then (recalling that $\pi \lambda=\frac{\bar{B}}{1-\bar{B}}+\pi$ )

$$
\begin{aligned}
& (1-\alpha)[\log (\bar{A}(\lambda(\pi), \pi))-\log (\bar{A}(1, \pi))] \\
= & \alpha \log \left(1+\frac{\bar{B}}{(1-\bar{B})} \frac{1}{\pi}\right)-\log \left(1+\frac{\bar{B}}{1-\bar{B} \frac{1}{\frac{1-\beta(1+r)}{\beta(r+\delta)}+\pi}}\right)
\end{aligned}
$$

Analyzing this equation, let $c=\frac{\bar{B}}{1-\bar{B}}, d=\frac{1-\beta(1+r)}{\beta(r+\delta)}$. Then I claim that

$$
f(\pi)=\log \left(1+c \pi^{-1}\right)-\log \left(1+c(d+\pi)^{-1}\right)
$$

is decreasing in $\pi$. To see this, we have

$$
\begin{aligned}
f^{\prime}(\pi) & =\frac{-c \pi^{-2}}{1+c \pi^{-1}}-\frac{-c(d+\pi)^{-2}}{1+c(d+\pi)^{-1}} \\
& =c\left[(d+\pi)^{-2}\left(1+c(d+\pi)^{-1}\right)^{-1}-\pi^{-2}\left(1+c \pi^{-1}\right)^{-1}\right]
\end{aligned}
$$

And we must have

$$
(d+\pi)^{-2}\left(1+c(d+\pi)^{-1}\right)^{-1} \leq \pi^{-2}\left(1+c \pi^{-1}\right)^{-1}
$$


since

$$
\begin{aligned}
\pi^{2}+c \pi & \leq(d+\pi)^{2}+c(d+\pi) \\
0 & \leq d^{2}+2 d \pi+c d
\end{aligned}
$$

And we have that $\beta(1+r) \leq 1$ so that $d \geq 0$ and $c \geq 0$.

What about output?

$$
\begin{aligned}
Y(\pi, \lambda) & =\left(\frac{1-\alpha}{w}\right)^{\frac{1-\alpha}{\alpha}} \pi \lambda \bar{A}(\pi, \lambda) \\
& =(\pi \lambda \bar{A}(\pi, \lambda))^{\alpha} \\
& =\left[\frac{\alpha \beta \pi \lambda}{1-\beta(1+r)+\beta(r+\delta) \pi \lambda}\right]^{\frac{\alpha}{1-\alpha}} \\
& =\left[\frac{\alpha \beta}{(1-\beta(1+r))(\pi \lambda)^{-1}+\beta(r+\delta)}\right]^{\frac{\alpha}{1-\alpha}}
\end{aligned}
$$

Then

$$
\begin{aligned}
& \frac{1-\alpha}{\alpha}[\log Y(\pi, \lambda(\pi))-\log (Y(\pi, 1))] \\
= & \log \left(\frac{1}{\pi}(1-\beta(1+r)+\beta(r+\delta))-\log \left(\frac{1}{\pi \lambda}(1-\beta(1+r))+\beta(r+\delta)\right)\right. \\
= & \log \left(\frac{1}{\pi} c_{1}+c_{2}\right)-\log \left(\frac{1}{\bar{c}+\pi} c_{1}+c_{2}\right)
\end{aligned}
$$

Differentiating with respect to $\pi$ we have

$$
\begin{aligned}
& \frac{-c_{1} \pi^{-2}}{\pi^{-1} c_{1}+c_{2}}-\frac{-c_{1}(\bar{c}+\pi)^{-2}}{(\bar{c}+\pi)^{-1} c_{1}+c_{2}} \\
= & c_{1}\left[\frac{1}{(\bar{c}+\pi) c_{1}+(\bar{c}+\pi)^{2} c_{2}}-\frac{1}{\pi c_{1}+\pi^{2} c_{2}}\right]
\end{aligned}
$$

which must be negative.

\section{Derivations for External Financing}

- Available Funds: 
- If $z_{t}=1$ then

$$
\begin{aligned}
A F_{t} & =\alpha\left(\frac{1-\alpha}{w}\right)^{\frac{1-\alpha}{\alpha}} k_{t}-r\left(k_{t}-a_{t}\right) \\
& =a_{t}\left[\lambda \alpha\left(\frac{1-\alpha}{w}\right)^{\frac{1-\alpha}{\alpha}}-r(\lambda-1)\right] \\
& =a_{t}\left[\frac{1-\beta(1+r)}{\beta \pi}+\lambda(r+\delta)-r \lambda+r\right] \\
& =a_{t}\left[\frac{1-\beta(1+r)}{\beta \pi}+\lambda \delta+r\right]
\end{aligned}
$$

If $z_{t}=0$ then

$$
A F_{t}=-r b_{t}=-r\left(-a_{t}\right)=r a_{t}
$$

- Investment

- If $z_{t}=z_{t+1}=\bar{z}$,

$$
\begin{aligned}
X_{t} & =\lambda a_{t+1}-(1-\delta) \lambda a_{t} \\
& =\lambda \beta\left\{\lambda\left[\alpha\left(\frac{1-\alpha}{w}\right)^{\frac{1-\alpha}{\alpha}}-(r+\delta)\right]+(1+r)\right\} a_{t}-(1-\delta) \lambda a_{t} \\
& =\lambda a_{t}\left[\beta \lambda \alpha\left(\frac{1-\alpha}{w}\right)^{\frac{1-\alpha}{\alpha}}-\beta \lambda(r+\delta)+\beta(1+r)-(1-\delta)\right] \\
& =\lambda a_{t}\left[\frac{1-\beta(1+r)}{\pi}+\beta \lambda(r+\delta)-\beta \lambda(r+\delta)+\beta(1+r)-(1-\delta)\right] \\
& =\lambda a_{t}\left[\delta+\frac{1-\pi}{\pi}(1-\beta(1+r))\right]
\end{aligned}
$$

- If $z_{t}=\bar{z}, z_{t+1}=0$,

$$
X_{t}=-(1-\delta) \lambda a_{t}
$$

- If $z_{t}=0, z_{t+1}=\bar{z}$,

$$
X_{t}=\lambda a_{t+1}=\lambda \beta(1+r) a_{t}
$$

- If $z_{t}=z_{t+1}=0, X_{t}=0$.

- $\mathrm{AF}-\mathrm{X}$

- If $z_{t}=z_{t+1}=0$,

$$
A F_{t}-X_{t}=r a_{t}
$$


- If $z_{t}=0, z_{t+1}=\bar{z}$,

$$
\begin{aligned}
A F_{t}-X_{t} & =r a_{t}-\lambda \beta(1+r) a_{t} \\
& =a_{t}[r-\lambda \beta(1+r)]
\end{aligned}
$$

- If $z_{t}=\bar{z}, z_{t+1}=0$,

$$
\begin{aligned}
A F_{t}-X_{t} & =a_{t}\left[\frac{1-\beta(1+r)}{\beta \pi}+\lambda \delta+r+(1-\delta) \lambda\right] \\
& =a_{t}\left[\frac{1-\beta(1+r)}{\beta \pi}+\lambda+r\right]
\end{aligned}
$$

- If $z_{t}=z_{t+1}=\bar{z}$,

$$
\begin{aligned}
A F_{t}-X_{t} & =a_{t}\left[\frac{1-\beta(1+r)}{\beta \pi}+\lambda \delta+r-\lambda\left[\delta+\frac{1-\pi}{\pi}(1-\beta(1+r))\right]\right] \\
& =a_{t}\left[\frac{1}{\beta \pi}(1-\beta(1+r))+\lambda \delta+r-\lambda \delta-\frac{\lambda(1-\pi)}{\pi}(1-\beta(1+r))\right] \\
& =a_{t}\left[r+(1-\beta(1+r))\left[\frac{1-\beta \lambda(1-\pi)}{\beta \pi}\right]\right]
\end{aligned}
$$




\section{Appendix C: Other Proofs}

\section{Proof of Lemma (2), Proposition (3) and Corollary (4).}

Publicly held firms solve

$$
\begin{aligned}
& \max E_{0} \sum_{t} \beta^{t} d_{t} \\
& d_{t}+a_{t+1} \leq f\left(z_{t}, k_{t}\right)+(1+r) a_{t} \\
& k_{t} \leq \lambda_{t} a_{t} \\
& d_{t} \geq 0
\end{aligned}
$$

or

$$
\max E_{0} \sum_{t} \beta^{t}\left[\left(f_{t}\left(z_{t}, k_{t}\right)+(1+r) a_{t}-a_{t+1}\right)\left(1+\eta\left(z^{t}\right)\right)+\mu\left(z^{t}\right)\left(\lambda a_{t}-k_{t}\right)\right]
$$

FOCs

$$
\begin{aligned}
f^{\prime}\left(z_{t}, k_{t}\right) & =\mu\left(z^{t}\right) \\
\left(1+\eta\left(z^{t}\right)\right) & =\beta E_{t}\left[(1+r)\left(1+\eta\left(z_{t+1}, z^{t}\right)\right)+\mu\left(z_{t+1}, z^{t}\right) \lambda\right]
\end{aligned}
$$

where the last can be re-written using $\beta(1+r)=1$ :

$$
\eta\left(z^{t}\right)=\beta E_{t}\left[(1+r) \eta\left(z_{t+1}, z^{t}\right)+\mu\left(z_{t+1}, z^{t}\right) \lambda\right]
$$

Thus, if $\eta\left(z_{t+1}, z^{t}\right)$ or $\mu\left(z_{t+1}, z^{t}\right)$ are positive for any $z_{t+1}$ with strictly positive probability following $z^{t}$ then $\eta\left(z^{t}\right)=0$ and

$$
a_{t+1}\left(z^{t}\right)=f\left(z_{t}, k_{t}\right)+(1+r) a_{t}
$$

Since $f \geq 0$ and $1+r>1$ we have that assets grow as long as constraints ever bind in the future.

Now, optimal unconstrained capital scale satisfies

$$
f^{\prime}\left(z_{t}, k_{t}\right)=0
$$

Let the optimal scale be defined as

$$
k^{*}(z)=\left(f^{\prime}\right)^{-1}(0, z)
$$

We can easily show that $k^{*}(z)$ is increasing in $z$. Suppose $z \in[\underline{z}, \bar{z}]$. Then, if $a_{t} \geq \lambda k^{*}(\bar{z})$, the 
constraint does not bind currently and choosing any $a_{t+1} \geq a_{t}$ will ensure that the constraint never binds again in the future. Suppose at time $s$ the firm's assets satisfy $a_{s} \geq \lambda k^{*}(z)$. In this case, the firm solves

$$
\max E_{s} \sum_{t \geq s} \beta^{t-s}\left[\left(f_{t}\left(z_{t}, k_{t}\right)+(1+r) a_{t}-a_{t+1}\right)\right]
$$

and since $\beta(1+r)=1$ this simplifies to

$$
E_{s} \sum_{t \geq s} \beta^{t-s}\left[\left(f_{t}\left(z_{t}, k_{t}\right)\right]+a_{t}(1+r)\right.
$$

Note then, in steady state that no publicly held firms will be constrained (assets are increasing until the constraint never binds and then are indeterminate above $\bar{a}$ ). Then, investment for any firm is simply

$$
k^{*}\left(z_{t+1}\right)-(1-\delta) k^{*}\left(z_{t}\right)
$$

Thus, investment is bounded above by

$$
k^{*}(\bar{z})-(1-\delta) k^{*}(\underline{z}) .
$$

However, available funds, in steady state, are not pinned down since they are equal to

$$
f\left(z_{t}, k^{*}\left(z_{t}\right)\right)-r\left(k^{*}\left(z_{t}\right)-a_{t}\right)
$$

Since the firm is indifferent between any $a_{t} \geq \bar{a}$, there are a continuum of equilibria with different steady state asset holdings of publicly held firms each corresponding to different amounts of external financing.

\section{Optimal Production and Savings Decisions of Privately Held Firms}

In this appendix, we provide a characterization of the privately held firm's optimal capital, labor, and savings decisions. The problem of a surviving privately held firm can be written recursively as 


$$
\begin{aligned}
& V_{u}(a, z)=\max _{c, a^{\prime}, k, l} u(c)+\beta \zeta E\left[V_{u}\left(a^{\prime}, z^{\prime}\right) \mid z\right] \\
& \text { s.t. } \\
& c+a^{\prime} \leq p(a, z) z^{\frac{1}{\rho-1}}\left(k^{\alpha} l^{1-\alpha}\right)^{\eta} I^{1-\eta}-w l-(r+\delta) k-I+(1+r) a \\
& p(a, z)=Q^{\frac{1}{\rho}}\left(z^{\frac{1}{\rho-1}}\left(k^{\alpha} l^{1-\alpha}\right)^{\eta} I^{1-\eta}\right)^{-\frac{1}{\rho}} \\
& k \leq \lambda a \\
& a_{0} \text { given }
\end{aligned}
$$

The decision of how much capital to install and how much labor to hire is a static one. We therefore can use the results from our static model, namely Lemma (7) to define profits of a privately held firm, which we denote $\Pi_{u}(a, z ; w, r, Q)$. Then the problem of an unlisted firm can be simplified to a consumption and savings problem written as

$$
\begin{aligned}
V^{u}(a, z)= & \max _{c, a^{\prime}} u(c)+\beta \zeta E\left[V^{u}\left(a^{\prime}, z^{\prime}\right) \mid z\right] \\
\text { s.t. } & \\
c+a^{\prime} \leq & \Pi_{u}(a, z ; w, r, Q)+(1+r) a
\end{aligned}
$$

As in Aiyagari (1994), the only intertemporal effect of the borrowing constraint comes from distorting the savings decisions. The nature of the borrowing constraint ensures that this happens in a smooth way. Thus, the optimal savings decision can be solved as in Aiyagari (1994), except for the extra term that captures the effect of savings on the next period's profit function. We then have the following proposition, in which we suppress the dependence of $\Pi_{u}$ on equilibrium parameters $w, r$, and $Q$ and write it only as $\Pi_{u}(a, z)$.

Lemma 11. For an unlisted firm, the optimal asset position policy is given by a function $a^{\prime}(a, z)$ that satisfies

$$
\begin{aligned}
& u^{\prime}\left(\Pi(a, z)+(1+r) a-a^{\prime}(a, z)\right) \\
= & \beta \zeta E\left\{\left[\Pi_{a}^{U}\left(a^{\prime}(a, z), z^{\prime}\right)+(1+r)\right] u^{\prime}\left(\Pi\left(a^{\prime}(a, z), z^{\prime}\right)+(1+r) a^{\prime}(a, z)-a^{\prime}\left(a^{\prime}(a, z), z^{\prime}\right)\right) \mid z\right\}
\end{aligned}
$$




\section{Appendix D: Figures}

Figure 3: Available Funds and Capital Expenditures normalized by Nonfinancial Corporate Business GDP, U.S. Nonfarm Nonfinancial Corporate Businesses. Source: U.S. Flow of Funds and BEA.

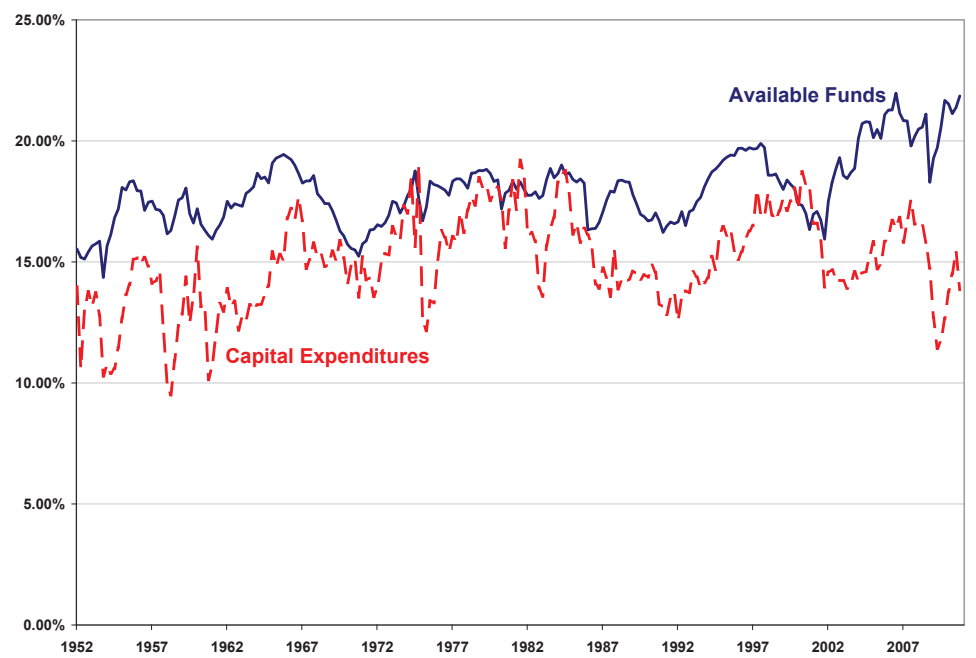

Figure 4: Available Funds, Internal Funds and Capital Expenditures normalized by Nonfinancial Corporate Business GDP, U.S. Nonfarm Nonfinancial Corporate Businesses. Source: U.S. Flow of Funds and BEA.

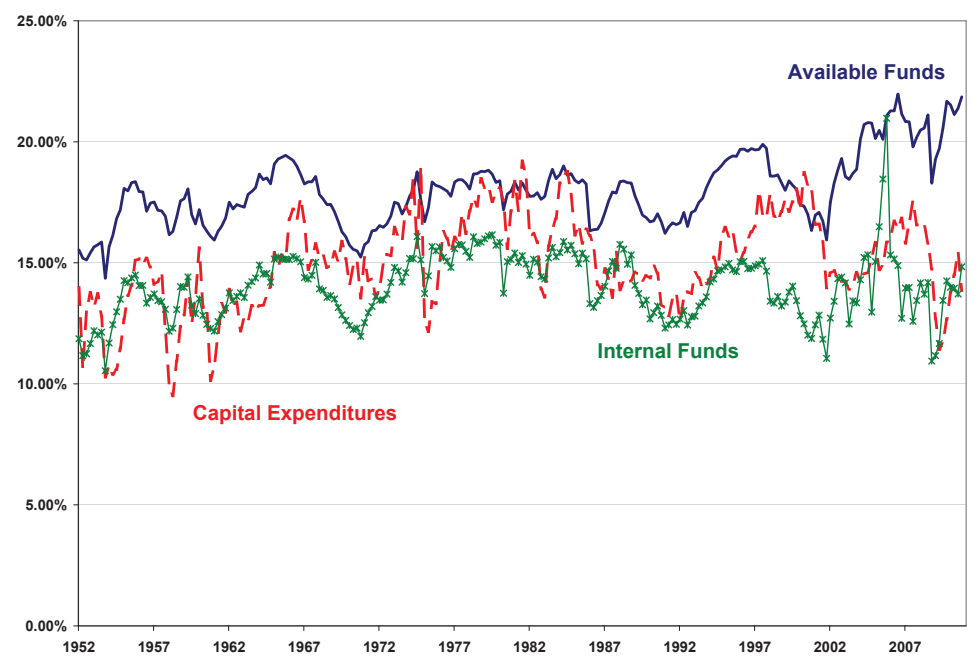


Figure 5: Available Funds and Capital Expenditures normalized by GDP, U.K. Nonfarm Nonfinancial Corporate Businesses. Source: U.K. National Accounts.

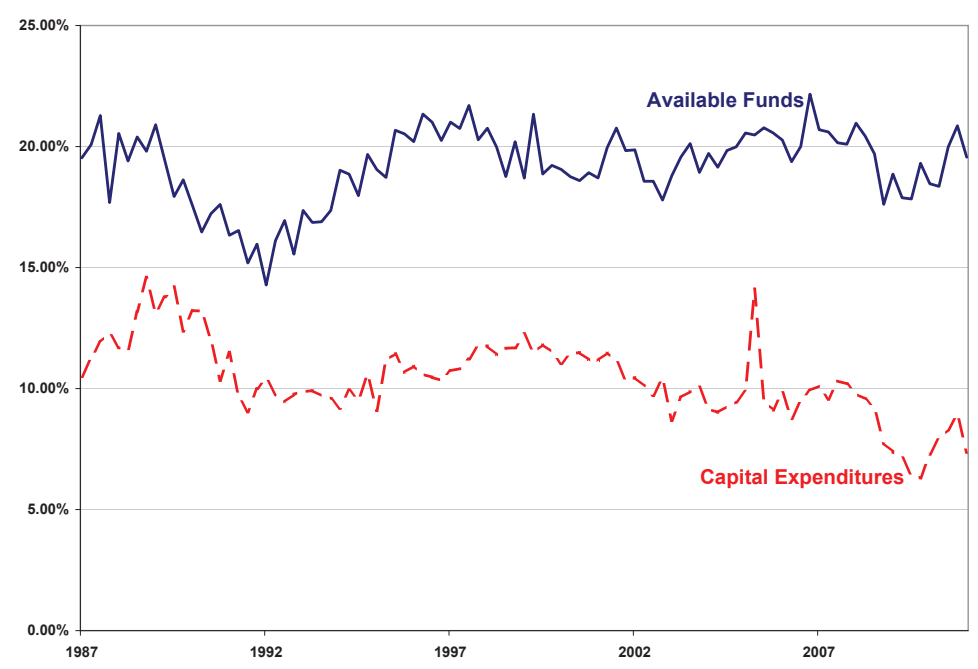

Figure 6: Available Funds, Internal Funds and Capital Expenditures normalized by GDP, U.K. Nonfarm Nonfinancial Corporate Businesses. Source: U.K. National Accounts.

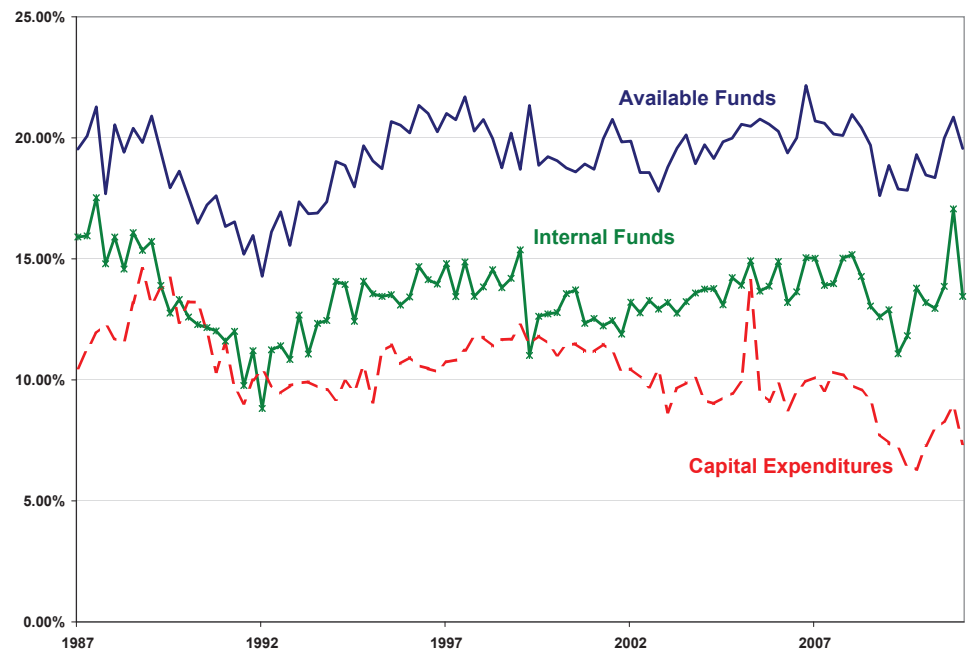


Figure 7: Fraction of Investment by Compustat U.S. Firms Financed by External Funds. Source: Compustat and Authors' calculations.

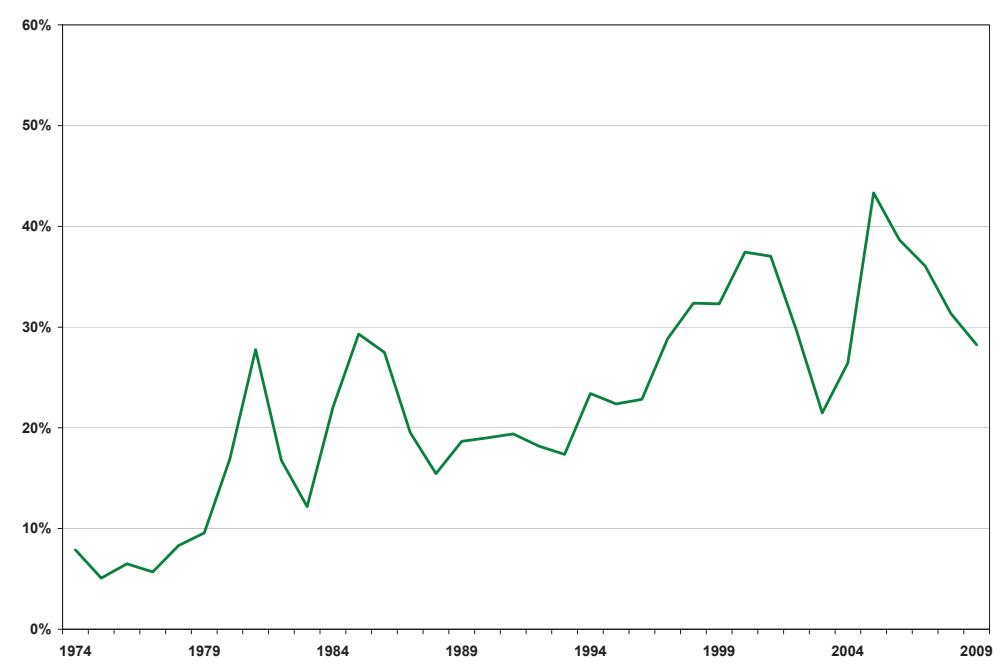

Figure 8: Fraction of Investment by Compustat U.K. Firms Financed by External Funds. Source: Compustat Global and Authors' calculations.

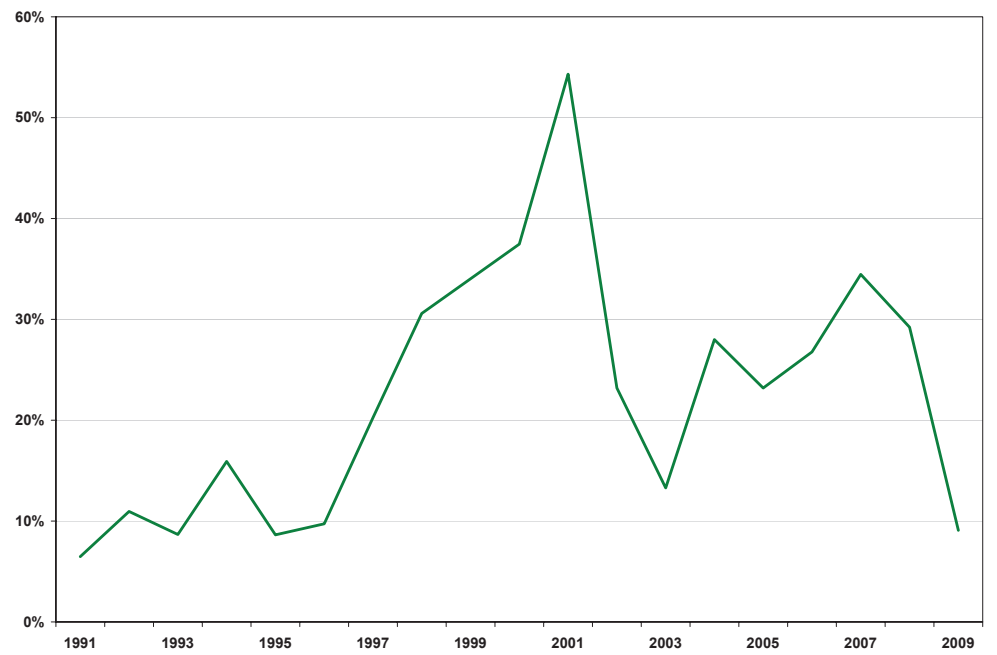


Figure 9: Fraction of Investment by Privately Held Firms in the U.K. Financed by External Funds. Source: Amadeus.

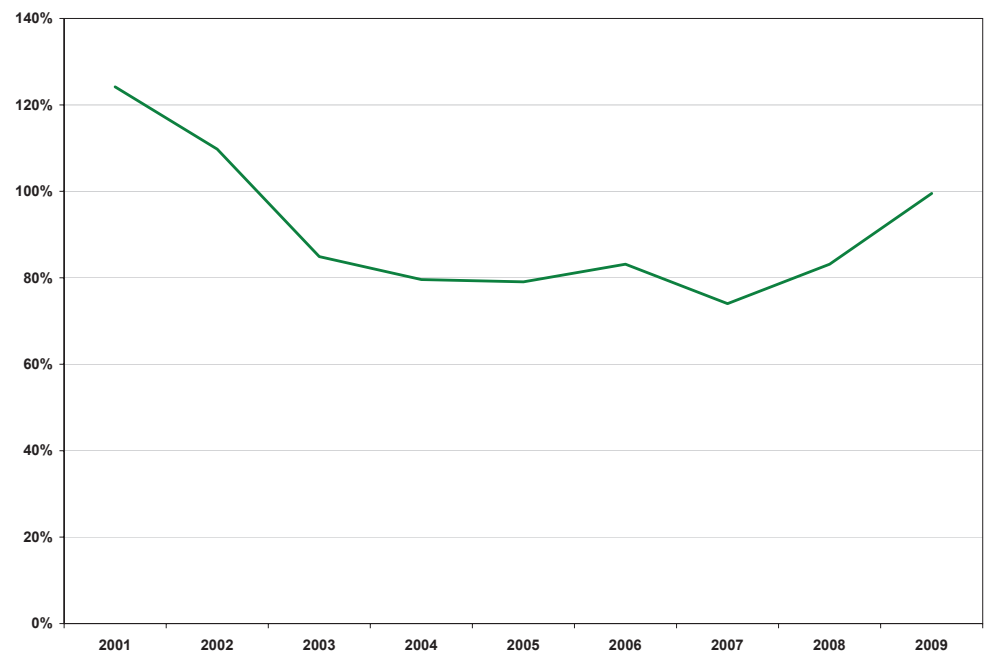

Figure 10: Available Funds and Investment of Compustat U.S. Firms normalized by U.S. Non-farm Non-financial Corporate Business GDP. Source: Compustat and BEA.

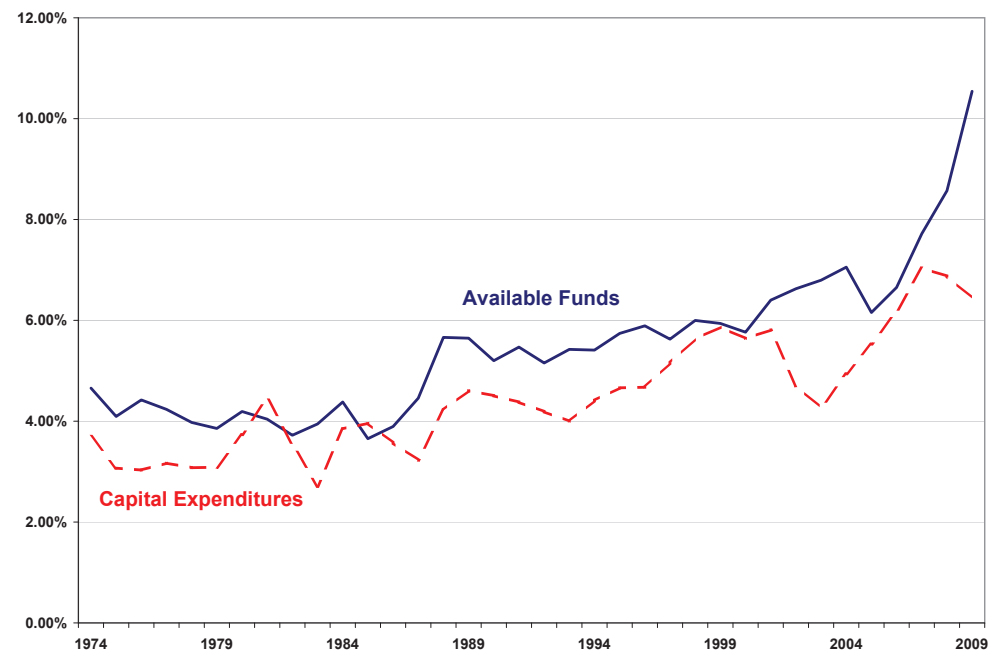


Figure 11: Available Funds and Investment of Compustat U.K. Firms normalized by GDP. Source: Compustat Global and U.K. National Accounts.

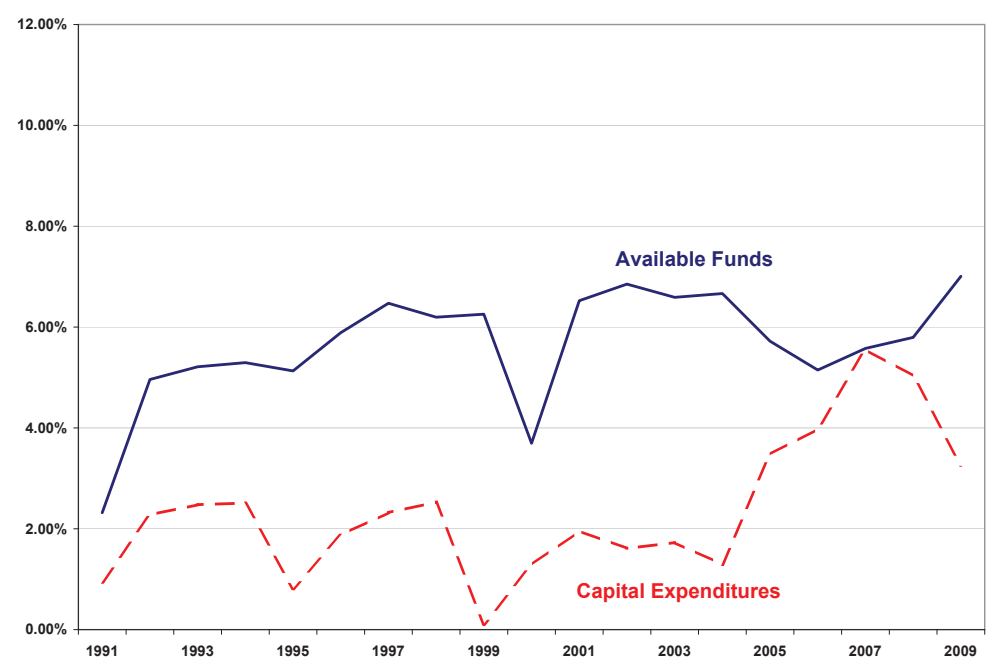

Figure 12: Available Funds and Investment of Privately Held Firms in the U.K. normalized by Aggregate Sales of such firms. Source: Amadeus.

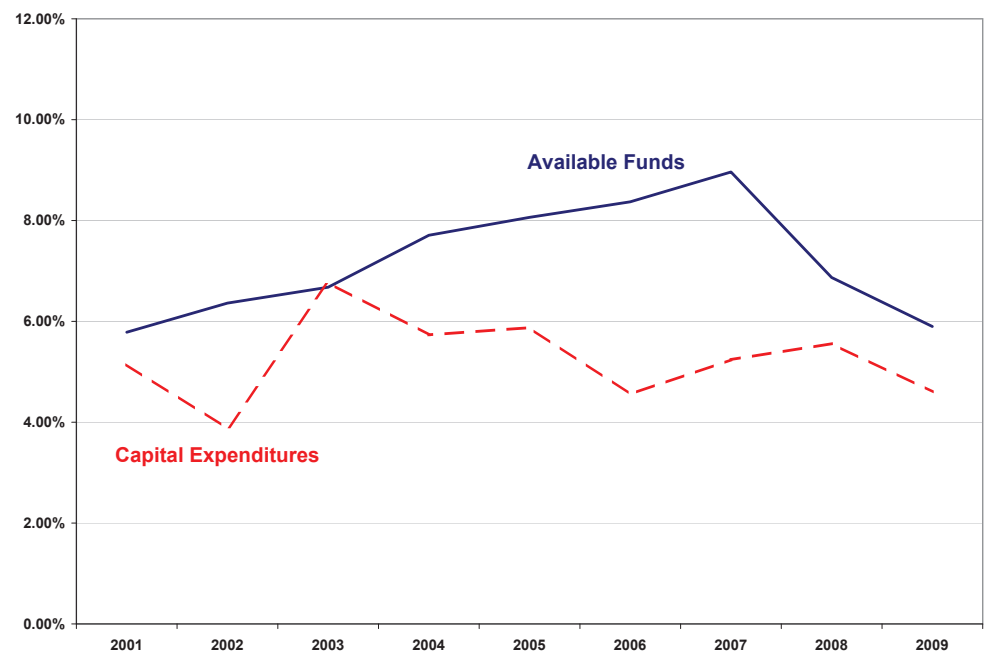


Figure 13: Aggregate Debt-to-Assets of U.S. Nonfarm Nonfinancial Corporate Businesses, deviations from HP-filtered trend. Source: U.S. Flow of Funds.

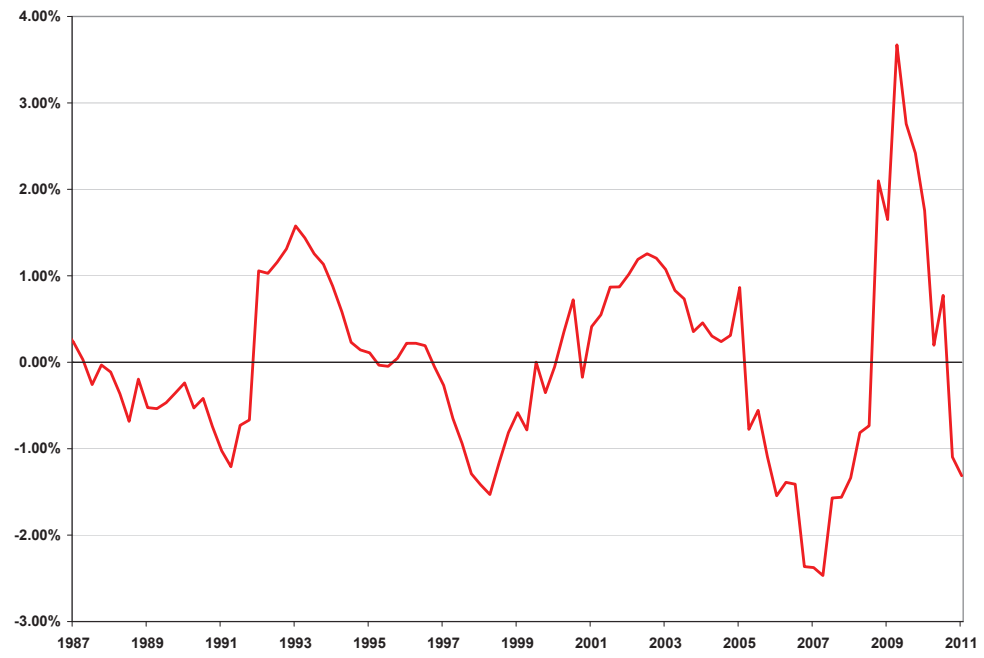

Figure 14: Gross Output of all Non-Financial Firms and all Non-Financial Firms in Compustat. Source: U.S. BEA and Compustat

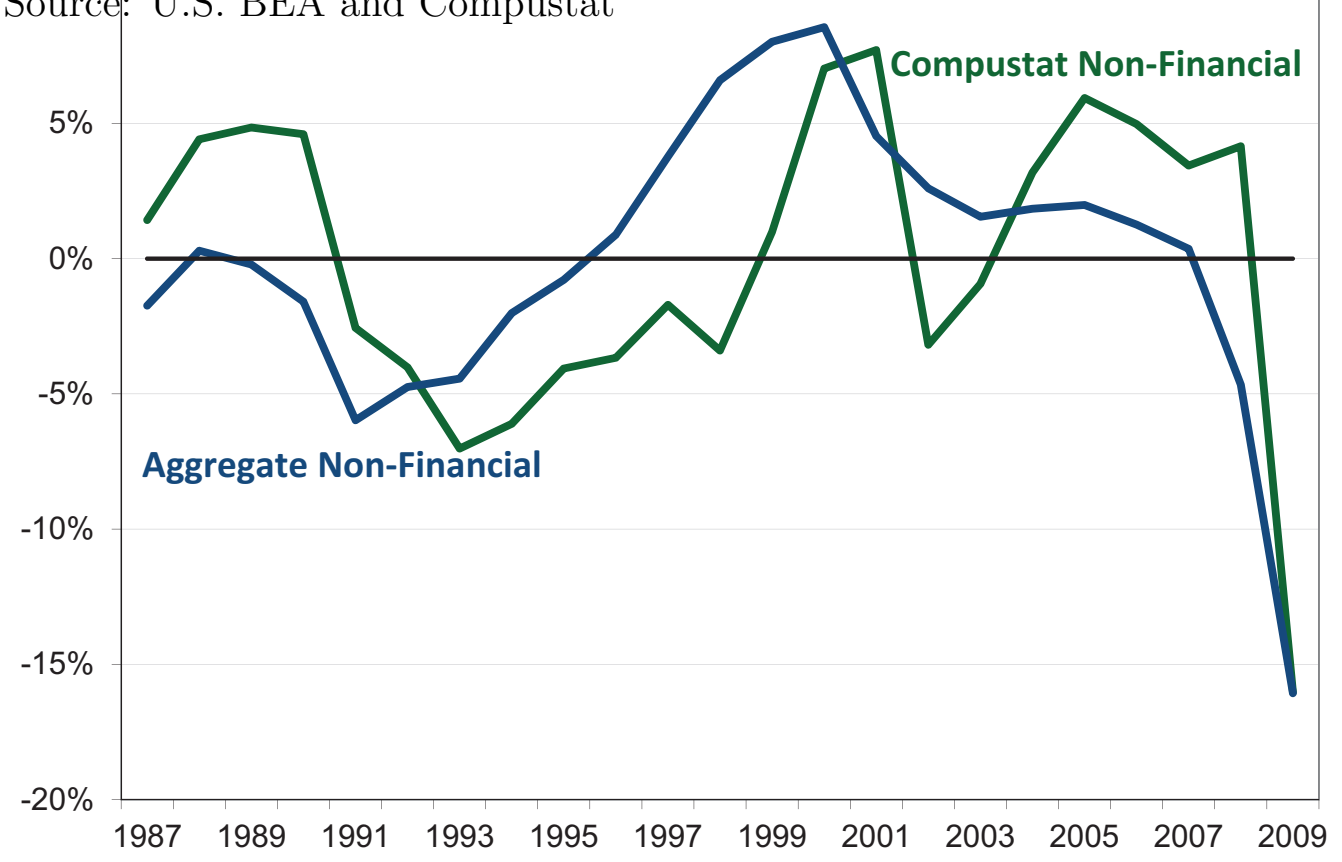


Figure 15: Share of all Non-Financial Gross Output Accounte for by all Non-Financial Firms in Compustat devaitions from a linear trend Source: U.S. BEA and Compustat

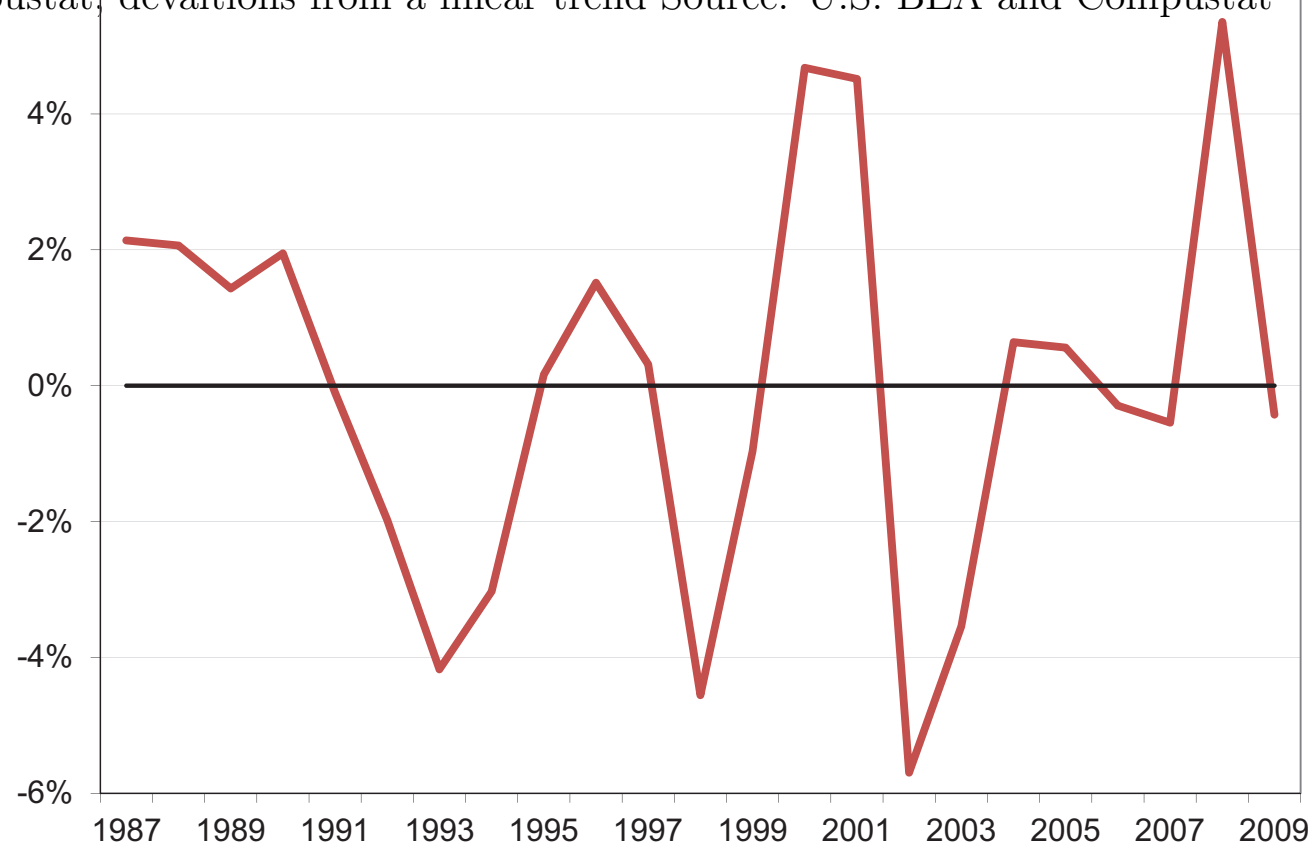



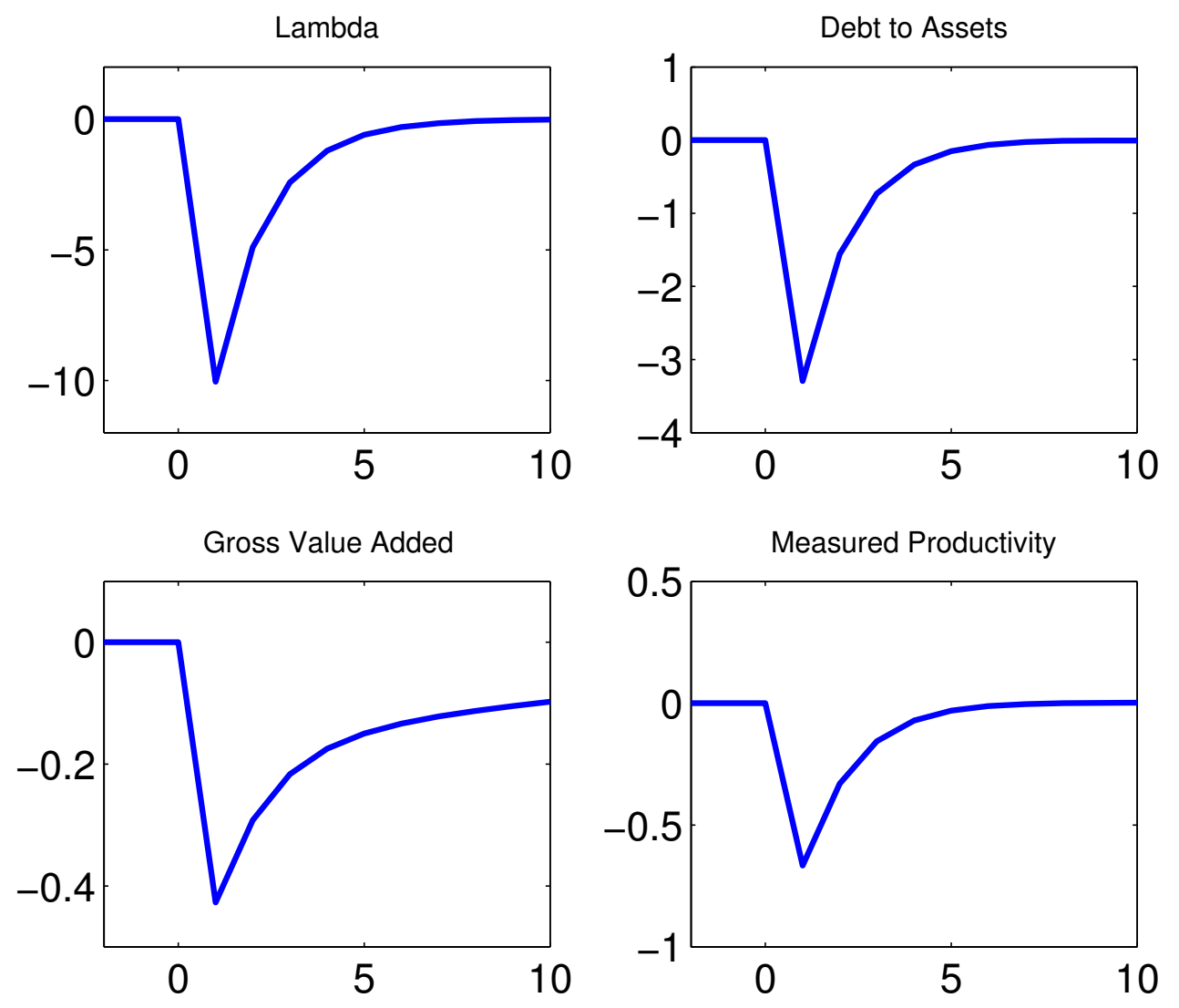

The $\mathrm{x}$-axis of each plot measures time in years.

The $y$-axis of each plot measures percentage point deviations from the steady state. 

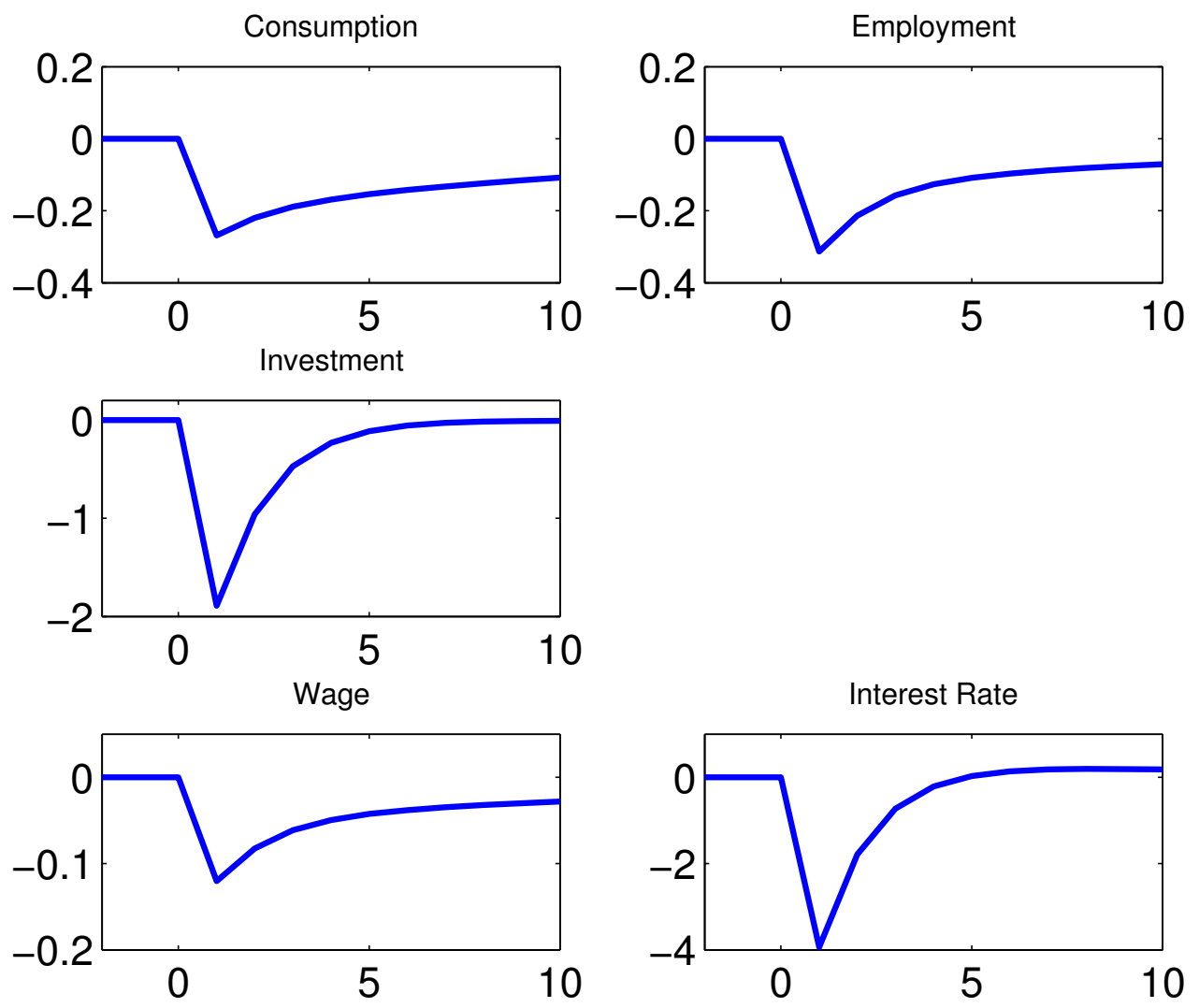

The $\mathrm{x}$-axis of each plot measures time in years.

The y-axis of each plot measures percentage point deviations from the steady state. 

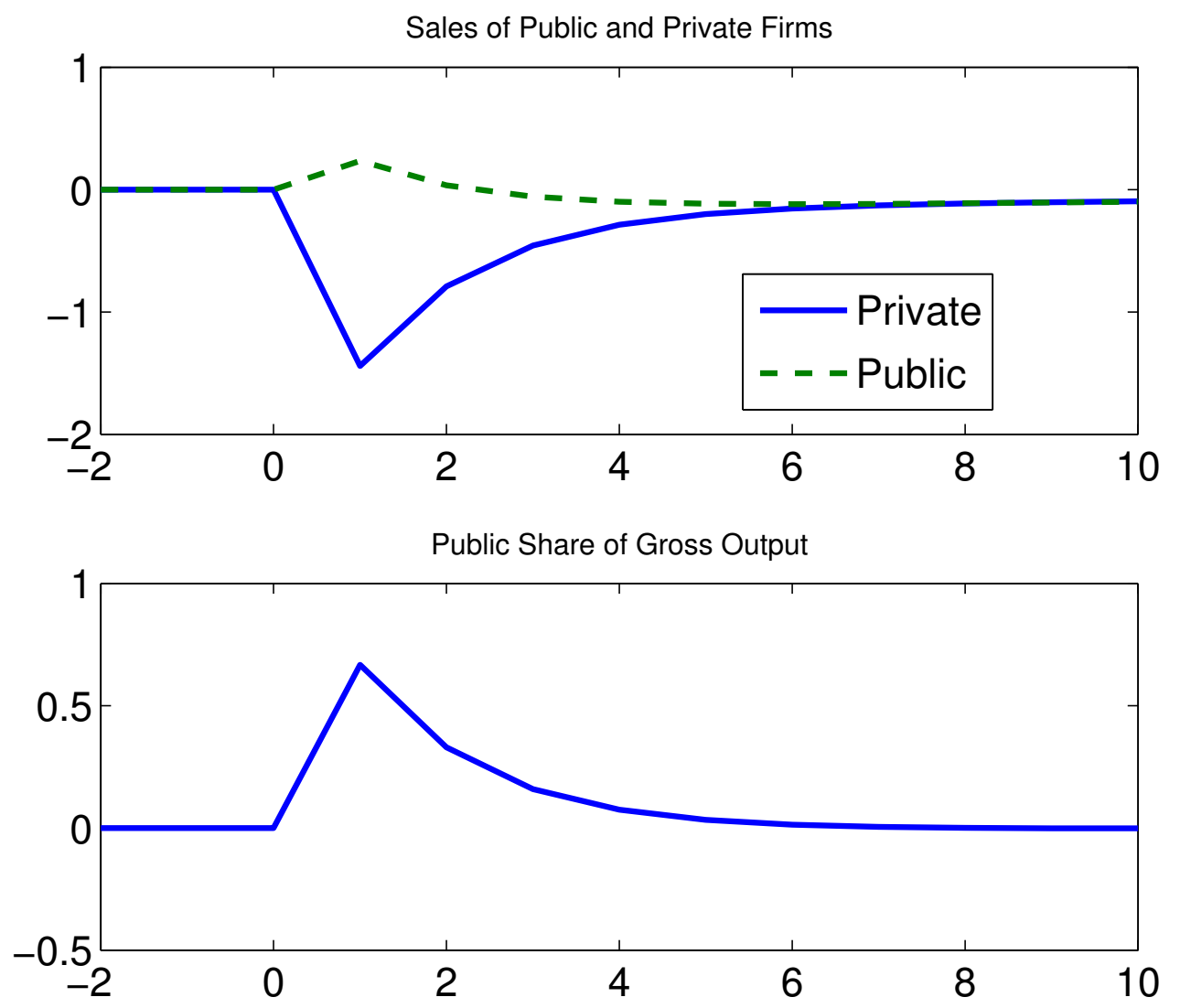

The $\mathrm{x}$-axis of each plot measures time in years.

The $y$-axis of each plot measures percentage point deviations from the steady state. 


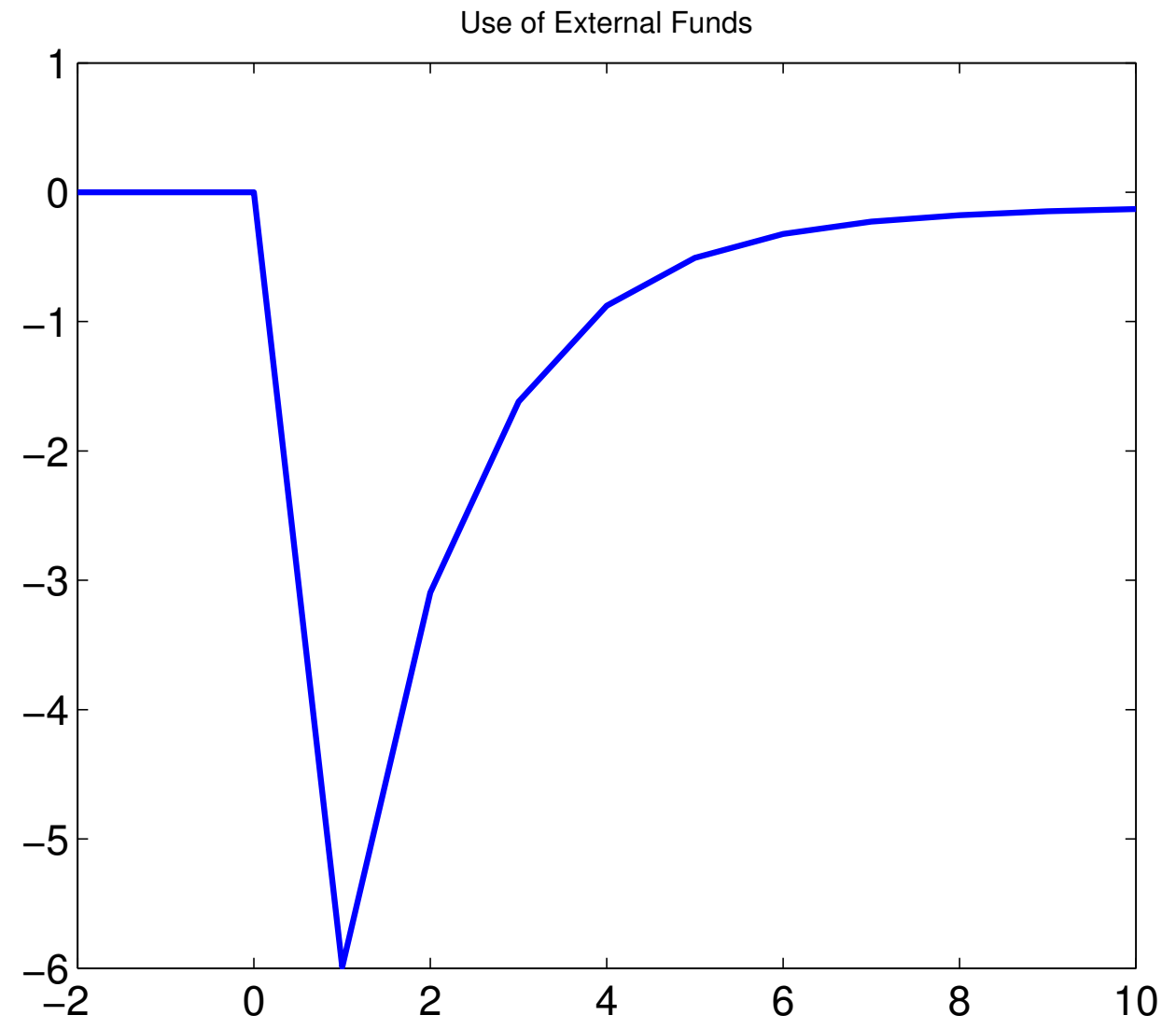

The $\mathrm{x}$-axis of each plot measures time in years.

The $y$-axis of each plot measures percentage point deviations from the steady state. 

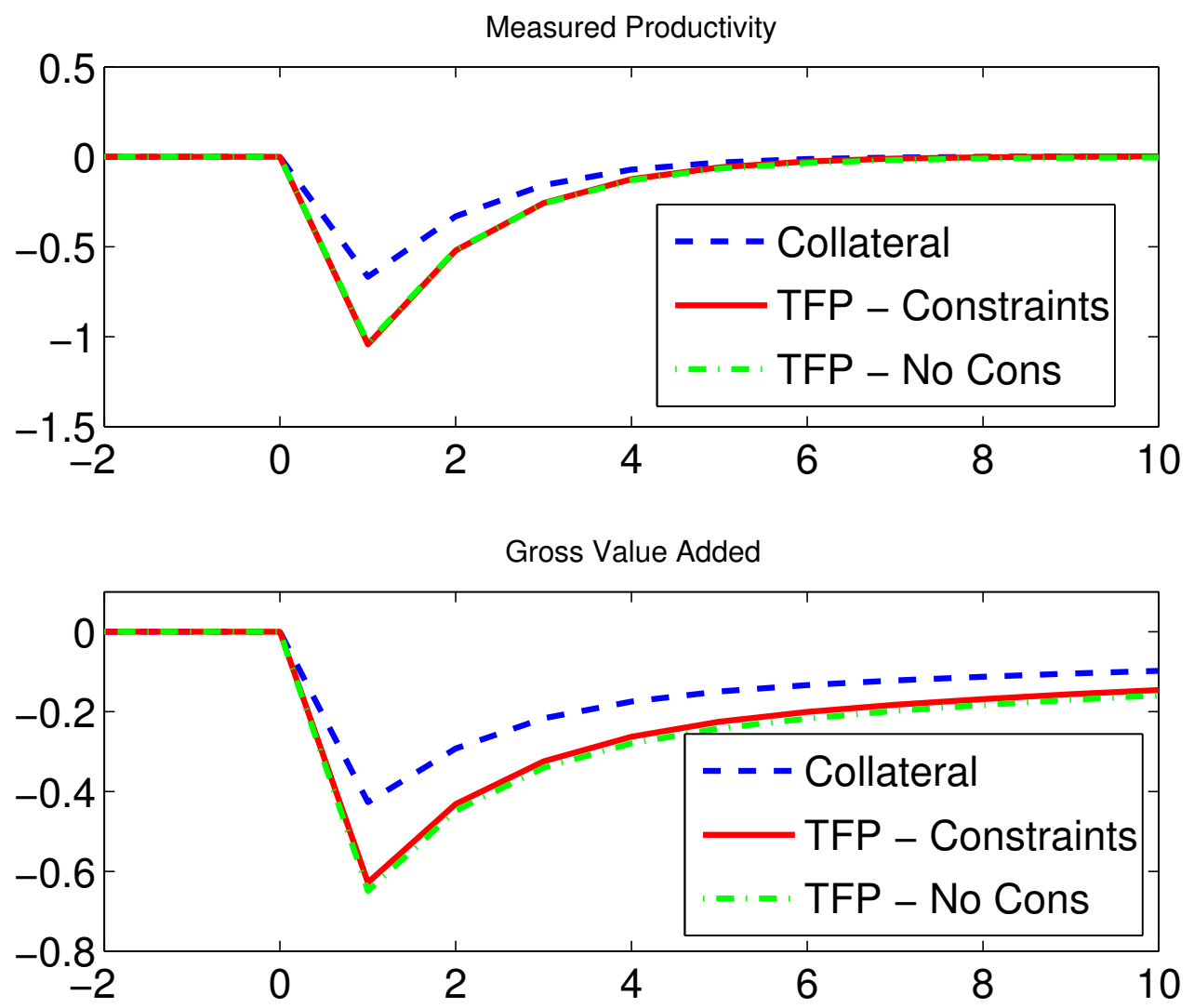

The $\mathrm{x}$-axis of each plot measures time in years.

The $y$-axis of each plot measures percentage point deviations from the steady state. 

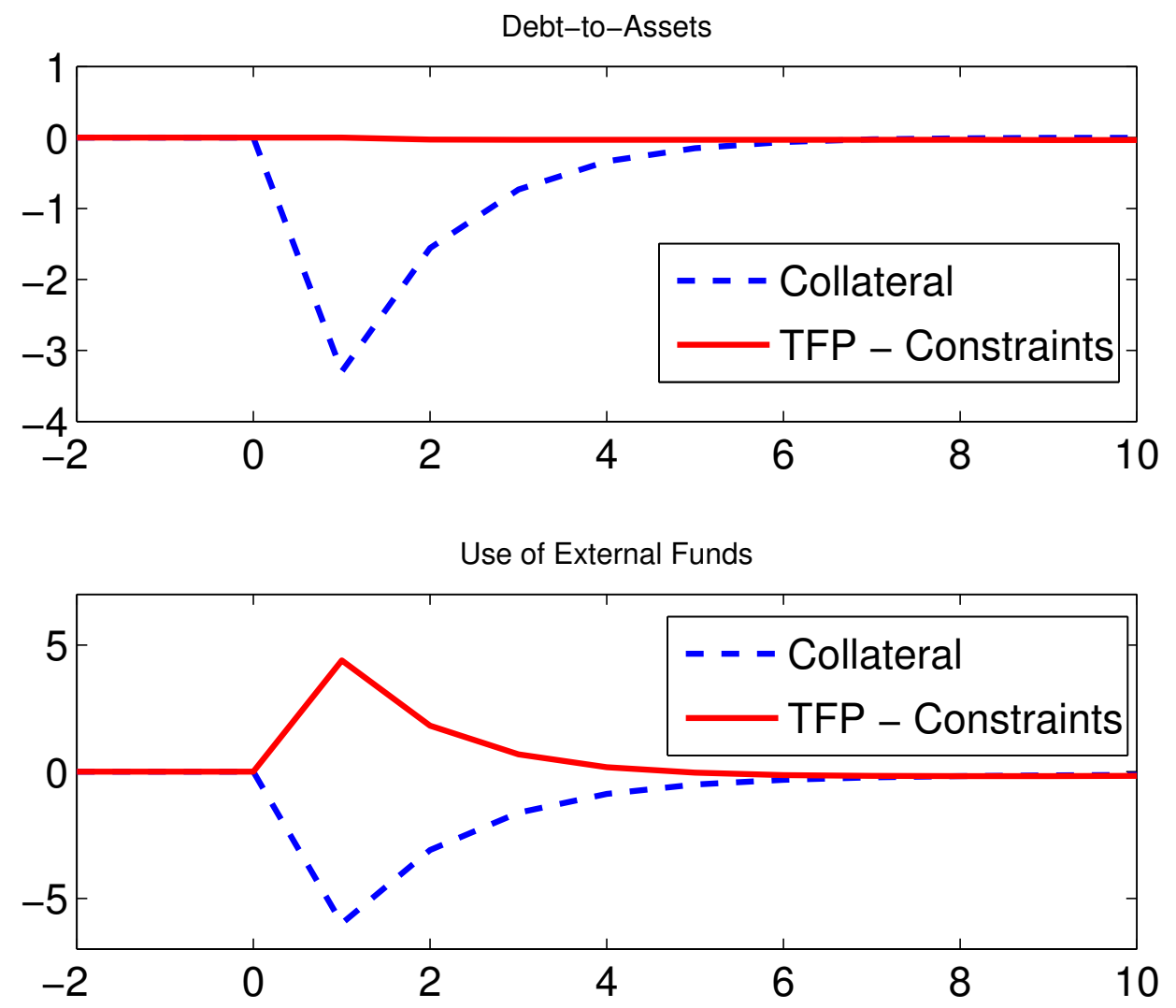

The $\mathrm{x}$-axis of each plot measures time in years.

The $y$-axis of each plot measures percentage point deviations from the steady state. 


\section{References}

AIYAGARI, S. (1994): "Uninsured idiosyncratic risk and aggregate saving," The Quarterly Journal of Economics, 109, 659.

Angeletos, G. (2007): "Uninsured Idiosyncratic Investment Risk and Aggregate Saving," Review of Economic Dynamics, 10, 1-30.

BASU, S. (1995): "Intermediate goods and business cycles: Implications for productivity and welfare," The American Economic Review, 512-531.

Bernanke, B. And M. Gertler (1989): "Agency Costs, Net Worth, and Business Fluctuations," American Economic Review, 79, 14-31.

Bernanke, B., M. Gertler, and S. Gilchrist (1999): "The Financial Accelerator in a Quantitative Business Cycle Framework," Handbook of Macroeconomics, edited by John B. Taylor and Michael Woodford, pp. 1341-1393, Amsterdam, New York and Oxford, Elsevier Science, North-Holland.

Buera, F., J. Kaboski, And Y. Shin (2011): "Finance and Development: A Tale of Two Sectors," American Economic Review, 101, 1964-2002.

Burstein, A. And C. Hellwig (2008): "Welfare Costs of Inflation in a Menu Cost Model," The American Economic Review, 98, 438-443.

Carlstrom, C. and T. Fuerst (1997): "Agency costs, net worth, and business fluctuations: A computable general equilibrium analysis," The American Economic Review, 893-910.

Chetty, R., A. Guren, D. Manoli, and A. Weber (2011): "Are Micro and Macro Labor Supply Elasticities Consistent? A Review of Evidence on the Intensive and Extensive Margins," American Economic Review, 101, 471-75.

Cooley, T. And V. Quadrini (2001): "Financial Markets and Firm Dynamics," American Economic Review, 91, 1286-1310.

Davis, S., J. Haltiwanger, R. Jarmin, and J. Miranda (2007): "Volatility and Dispersion in Business Growth Rates: Publicly Traded versus Privately Held Firms," NBER Macroeconomics Annual, 107.

Dunne, T., M. Roberts, and L. Samuelson (1988): "Patterns of firm entry and exit in US manufacturing industries," The RAND Journal of Economics, 495-515. 
Evans, D. And B. Jovanovic (1989): "An Estimated Model of Entrepreneurial Choice Under Liquidity Constraints," The Journal of Political Economy, 808-827.

Fazzari, S. M., R. G. Hubbard, and B. . Petersen (1988): "Financing Constraints and Corporate Investment," Brookings Papers on Economic Activity, 1988, 141-206.

Gertler, M. And S. Gilchrist (1994): "Monetary Policy, Business Cycles, and the Behavior of Small Manufacturing Firms," The Quarterly Journal of Economics, 109, 309.

Gilchrist, S. And C. Himmelberg (1995): "Evidence on the Role of Cash Flow for Investment," Journal of Monetary Economics, 36, 541-572.

Gomes, J. (2001): "Financing Investment," American Economic Review, 1263-1285.

Greenwood, J., Z. Hercowitz, and G. Huffman (1988): "Investment, capacity utilization, and the real business cycle," The American Economic Review, 402-417.

Guerrieri, V. And G. Lorenzoni (2011): "Credit Crises, Precautionary Savings and the Liquidity Trap," NBER Working Paper.

Hennessy, C. And T. Whited (2005): "Debt Dynamics," The Journal of Finance, 60, $1129-1165$.

Huggett, M. (1993): "The risk-free rate in heterogeneous-agent incomplete-insurance economies," Journal of economic Dynamics and Control, 17, 953-969.

Jermann, U. And V. Quadrini (2011): "Macroeconomic Effects of Financial Shocks," American Economic Review, forthcoming.

Jones, C. (2011): "Misallocation, Economic Growth, and Input-Output Economics," NBER Working Paper.

Kaplan, S. And L. Zingales (1997): "Do investment-cash flow sensitivities provide useful measures of financing constraints?" The Quarterly Journal of Economics, 112, 169.

Khan, A. And J. Thomas (2011): "Credit Shocks and Aggregate Fluctuations in an Economy with Production Heterogeneity," Tech. rep., National Bureau of Economic Research.

Kiyotaki, N. And J. Moore (1997): "Credit Cycles," Journal of political economy, 105, $211-248$.

- (2008): "Liquidity, business cycles, and monetary policy," Unpublished manuscript, Princeton University and Edinburgh University. 
Kocherlakota, N. (2009): "Bursting bubbles: Consequences and cures," Federal Reserve Bank of Minneapolis Mimeo.

Midrigan, V. AND D. XU (2010): "Finance and Misallocation: Evidence from Plant-Level Data," National Bureau of Economic Research Working Paper.

Moll, B. (2011): "Productivity Losses from Financial Frictions: Can Self-Financing Undo Capital Misallocation?" Princeton University mimeo.

Nezafat, M. and C. Slavik (2011): "Asset Prices and Business Cycles with Financial Shocks," Working Paper, University of Minnesota.

Rajan, R. And L. Zingales (1998): "Financial Dependence and Growth," The American Economic Review, 88, 559-586. 